\title{
Hygrothermal properties of unfired earth bricks: effect of barley straw, hemp shiv and corn cob addition
}

A. Laborel-Préneron ${ }^{\mathrm{a}^{*}}$, C. Magniont ${ }^{\mathrm{a}}, \mathrm{J}-\mathrm{E}$. Aubert $^{\mathrm{a}}$

a LMDC, INSA/UPS Génie Civil, 135 Avenue de Rangueil, 31077 Toulouse cedex 04, France.

*Corresponding author: aurelie.laborel@gmail.com

Declarations of interest: none

\section{ABSTRACT}

Earth is a material presenting good hygric properties, which is an important point as comfort and indoor air quality have become major issues. Nowadays, the energy efficiency of a construction is also crucial, but the thermal insulation provided by an earth brick is quite low. Therefore, some plant aggregates were added to lighten the material, thus decreasing its thermal conductivity. The hygrothermal properties of seven formulations made of earth with 0,3 or $6 \%$ by weight content of barley straw, hemp shiv or corn cob were assessed. The properties determined were thermal conductivity, specific heat capacity, water vapour permeability, and sorption-desorption isotherms measured with the saturated salt solution and DVS methods. The theoretical MBV was also calculated. The study showed a large decrease in thermal conductivity when a large volume of plant aggregates was added while plant aggregates incorporation conversely affected the thermal inertia parameters. Concerning water vapour permeability, as earth is a very permeable material, the addition of plant aggregates did not improve this property. The sorption capacity of bio-based earth materials was slightly increased in comparison with earth alone. Finally, the calculated MBV showed the excellent buffering capacity of this kind of material, with and without plant aggregates. 
Keywords: earth brick, plant aggregate, thermal conductivity, specific heat capacity, sorptiondesorption isotherm, water vapour permeability, Moisture Buffer Value, hygrothermal performance

Highlights:

- Thermal conductivity decreases with the addition of plant aggregates.

- Earth material is highly water vapour permeable.

- Sorption-desorption isotherms are assessed with DVS and saturated salt solution methods.

- MBV of earth-based materials is excellent.

Nomenclature

\begin{tabular}{|c|c|}
\hline \multicolumn{2}{|c|}{ Latin symbols } \\
\hline A & Exposed surface area $\left(\mathrm{m}^{2}\right)$ \\
\hline $\mathrm{b}_{\mathrm{m}}$ & Moisture effusivity $\left(\mathrm{kg} \cdot \mathrm{m}^{-2} \cdot \mathrm{Pa}^{-1} \cdot \mathrm{s}^{-1 / 2}\right)$ \\
\hline$C_{p}$ & Specific heat capacity $\left(\mathrm{J} \cdot \mathrm{kg}^{-1} \cdot \mathrm{K}^{-1}\right)$ \\
\hline $\mathrm{D}$ & Diffusivity $\left(\mathrm{m}^{2} \cdot \mathrm{s}^{-1}\right)$ \\
\hline $\mathrm{dm}$ & Mass variation $(\mathrm{g})$ \\
\hline $\mathrm{dt}$ & Time variation (min) \\
\hline $\mathrm{E}$ & Effusivity $\left(\mathrm{J} \cdot \mathrm{K}^{-1} \cdot \mathrm{m}^{-2} \cdot \mathrm{s}^{-1 / 2}\right)$ \\
\hline $\mathrm{e}$ & Thickness of the specimen $(\mathrm{m})$ \\
\hline $\mathrm{e}_{\mathrm{a}}$ & Thickness of the air layer between the sample and the salt solution (m) \\
\hline $\mathrm{G}$ & Transmission rate of water vapour $\left(\mathrm{kg} \cdot \mathrm{s}^{-1}\right)$ \\
\hline $\mathrm{M}$ & Mass proportion (\%) \\
\hline $\mathrm{MBV}_{\text {ideal }}$ & Theoretical Moisture Buffer Value $\left(\mathrm{g} \cdot \mathrm{m}^{-2} . \% \mathrm{RH}^{-1}\right)$ \\
\hline $\mathrm{p}$ & Atmospheric pressure $(\mathrm{hPa})$ \\
\hline$p_{0}$ & Standard atmospheric pressure $(\mathrm{hPa})$ \\
\hline $\mathrm{Q}$ & Heat input (W) \\
\hline $\mathrm{R}$ & Gas constant for water vapour (N.M. $\left.\mathrm{kg}^{-1} \cdot \mathrm{K}^{-1}\right)$ \\
\hline $\mathrm{RH}_{1}$ & Relative humidity inside the cup (\%) \\
\hline $\mathrm{RH}_{2}$ & Relative humidity outside the cup (\%) \\
\hline S & Cross section $\left(\mathrm{m}^{2}\right)$ \\
\hline $\mathrm{T}$ & Temperature $(\mathrm{K})$ \\
\hline$t_{p}$ & Time period $(\mathrm{s})$ \\
\hline $\mathrm{V}$ & Volume proportion (\%) \\
\hline $\mathrm{u}$ & Moisture content $\left(\mathrm{kg}^{\mathrm{kg}} \mathrm{kg}^{-1}\right)$ \\
\hline $\mathrm{w}_{\mathrm{opt}}$ & Optimum moisture content (\%) \\
\hline$x$ & Proportion by mass of the composite components (\%) \\
\hline \multicolumn{2}{|c|}{ Greek symbols } \\
\hline$\Delta \mathrm{p}$ & Vapour pressure difference across the sample $(\mathrm{Pa})$ \\
\hline$\Delta T$ & $\begin{array}{l}\text { Temperature difference between the plates of the guarded hot plate apparatus } \\
(\mathrm{K})\end{array}$ \\
\hline$\delta$ & Water vapour permeability $\left(\mathrm{kg} \cdot \mathrm{m}^{-1} \cdot \mathrm{s}^{-1} \cdot \mathrm{Pa}^{-1}\right)$ \\
\hline
\end{tabular}




\begin{tabular}{|l|l|}
\hline$\delta_{a}$ & Water vapour permeability of the air $\left(\mathrm{kg} \cdot \mathrm{m}^{-1} \cdot \mathrm{s}^{-1} \cdot \mathrm{Pa}^{-1}\right)$ \\
\hline$\theta$ & Temperature $\left({ }^{\circ} \mathrm{C}\right)$ \\
\hline$\lambda$ & Thermal conductivity $\left(\mathrm{W} \cdot \mathrm{m}^{-1} \cdot \mathrm{K}^{-1}\right)$ \\
\hline$\mu$ & Water vapour diffusion resistance factor $(-)$ \\
\hline$\rho_{d}$ & Dry density $\left(\mathrm{kg} \cdot \mathrm{m}^{-3}\right)$ \\
\hline$\sigma_{c}$ & Compressive strength $(\mathrm{MPa})$ \\
\hline$\Phi$ & Relative humidity $(-)$ \\
\hline$\xi$ & Moisture capacity $\left(\mathrm{kg} \cdot \mathrm{kg}^{-1}\right)$ \\
\hline
\end{tabular}

\section{INTRODUCTION}

Research is currently focusing on the reduction of energy consumption and the improvement of hygrothermal comfort during the construction phase and the service life of buildings. Earth is a construction material that meets this major challenge. With its numerous assets such as its availability, recyclability and the low energy required for the transformation process and transportation, earth is increasingly being studied. One of its main qualities is its ability to regulate indoor moisture and improve the comfort of the building's users thanks to its hygroscopic properties [1]-[4]. These properties are also very important for human health. Poor moisture regulation can engender fungal growth leading to several diseases such as allergies or rhinitis [5], [6].

Any porous material construction exchanges water vapour with its environment [7]. It has been shown that earth, specifically, is able to store a considerable amount of moisture through the phenomena of surface adsorption (monolayer or multilayer) and capillary condensation [8]. Some authors believe that earth materials can be considered as natural air-conditioners [9]. The hygric regulation through moisture transport and storage can be quantified by measuring the water vapour permeability and the sorption-desorption isotherms, for example. These two tests are performed under stationary conditions and are useful to give data for Heat, Air and Moisture (HAM) models [7], [10]. They also allow a theoretical Moisture Buffer Value ( $\mathrm{MBV}_{\text {ideal }}$, a dynamic hygric property) to be calculated [4], [8], [11].

Earth can store heat but is not a good thermal insulator [1]. The addition of plant aggregates to improve thermal insulation of the material is thus the subject of more and more studies 
[12]-[16]. Their effect is mainly evaluated by measuring the thermal conductivity. It has been extensively demonstrated that an increase in plant aggregate content leads to a decrease in thermal conductivity [12], [14], [15], [17]. For example, the thermal conductivity of an earthen plaster containing about $16 \%$ by weight of barley straw was reduced by about $56 \%$ in comparison with a specimen made only of earth $\left(0.154\right.$ and $0.350 \mathrm{~W} \cdot \mathrm{m}^{-1} \cdot \mathrm{K}^{-2}$ respectively) [18]. It has also been shown that thermal conductivity depends on the moisture content of the material tested [14], [19]-[21] and on its porosity [19], [22]. Concerning thermal inertia, recent studies pointed out the good performance of earthen materials and the consequent improvement of indoor thermal comfort [23]-[25]. Nevertheless, no reference was found concerning the effect of plant aggregate content on the thermal inertia parameters of earth products. Abanto et al. [26] measured specific heat capacity and thermal diffusivity of different Peruvian adobe but no relation could be established between these properties and the adobe straw content.

However, hygric properties of earth composite materials including plant aggregates and their efficiency to regulate the indoor climate remain to be proved and few papers have studied this aspect.

The sorption-desorption isotherm curves describe the Equilibrium Moisture Content (EMC) of a material when it is exposed to a given Relative Humidity $(\mathrm{RH})$. Different methods exist to evaluate the sorption capacity of a material. In the standardized method of Saturated Salt Solutions (SSS) described in NF EN ISO 12571 [27], the various $\mathrm{RHs}$ are regulated by saturated salt solutions. The main advantage of this technique is that various samples can be tested at the same time and there is no upper size limit. Another method is Dynamic Vapour Sorption (DVS), in which $\mathrm{RH}$ is regulated by a nitrogen flow. A small sample is weighed continuously by a microbalance. This technique was first used in the pharmaceutical field and the agri-food industry but is now being increasingly used to assess the sorption capacity of building materials [7], [28]-[31]. However, it is controversial because the size of the sample is very small and building materials tend to be heterogeneous [4], [32]. These two methods were quantitatively compared by Bui et al. [7]. Both methods showed comparable 
results for the sorption capacity of barley straw but low correspondence between SSS and DVS techniques was found on corn flakes [31].

The present paper deals with the influence of the nature of plant aggregates and their content on the hygrothermal properties of earth materials. Three plant aggregates, barley straw, hemp shiv and corn cob, were added to an earth matrix to obtain weight contents of 0 to $6 \%$. This experimental study presents the results of thermal conductivity and specific heat capacity measurements together with two hygric properties: water vapour permeability and EMC, with an assessment of the sorption-desorption isotherms. The sorption-desorption curves were plotted from measurements made with both methods, SSS and DVS. The two methods were qualitatively compared in order to determine whether small samples could be representative of heterogeneous materials. Finally, the $\mathrm{MBV}_{\text {ideal }}$ was calculated from the two steady-state hygric properties measured (permeability and sorption capacity) in order to evaluate the impact of plant aggregates on the moisture buffering capacity of the composites.

\section{MATERIALS AND METHODS}

\subsection{Raw materials}

The materials used in this study were earth, as the main matrix, and three plant aggregates: barley straw, hemp shiv and corn cob. The earth was waste generated by the washing of limestone aggregates produced for the concrete industry, called quarry fines from aggregate washing processing (FWAS). The sludge created is left to dry in sedimentation basins and is then reduced to powder and used. These fines were composed of calcite (60\%), kaolinite (11\%), illite (11\%), quartz (10\%), dolomite (6\%) and goethite (3\%). FWAS were extremely fine: $99 \%$ of the particles by mass were below $80 \mu \mathrm{m}$ and the average particle size (D50) determined using pipette analysis was $6.5 \mu \mathrm{m}$. Some physical properties of plant aggregates, determined in a previous study [33], are recapitulated in Table 1. 
Table 1. Physical properties of the plant aggregates

\begin{tabular}{cccc}
\hline Material & Barley straw & Hemp shiv & Corn cob \\
\hline Designation & $\mathrm{S}$ & $\mathrm{H}$ & $\mathrm{CC}$ \\
Bulk density $\left(\mathrm{kg} \cdot \mathrm{m}^{-3}\right)$ & $57 \pm 1$ & $153 \pm 2$ & $497 \pm 14$ \\
Water absorption (\%) & $414 \pm 4$ & $380 \pm 11$ & $123 \pm 2$ \\
Diameter* $(\mathbf{m m})$ & $2.3 \pm 1.5$ & $2.0 \pm 1.2$ & $2.6 \pm 0.4$ \\
Thermal conductivity & $0.044 \pm 0.001$ & $0.051 \pm 0.002$ & $0.096 \pm 0.001$ \\
$\left(\mathrm{~W} \cdot \mathrm{m}^{-1} \cdot \mathrm{K}^{-1}\right)$ & & & \\
\hline
\end{tabular}

${ }^{*}$ Corresponding to average minor axis by image analysis

\subsection{Manufacturing process}

The hygrothermal properties were assessed on seven different formulations: a reference material made of FWAS only and composite materials made with $3 \%$ or $6 \%$ by weight content of one of the plant aggregates. The manufacturing process and the main mechanical properties have been described in a previous article [34]. Table 2 recapitulates the different proportions of the plant aggregates, the optimum moisture content $\left(\mathrm{w}_{\mathrm{opt}}\right)$, determined by the Proctor test, and the compressive strength $\left(\sigma_{c}\right)$ of the blocks studied.

Table 2. Composition and properties of the specimens

\begin{tabular}{cccc}
\hline Block formulation & $\begin{array}{c}\text { Proportion of plant } \\
\text { aggregate (\%) }\end{array}$ & $\mathbf{w}_{\text {opt }}(\%)$ & $\boldsymbol{\sigma}_{\mathrm{c}}(\mathrm{MPa})$ \\
\hline FWAS & 0 & 14 & $4.0 \pm 0.4$ \\
S3 & 3 & 19 & $3.3 \pm 0.2$ \\
H3 & 3 & 17 & $2.4 \pm 0.2$ \\
CC3 & 3 & 16 & $3.2 \pm 0.2$ \\
S6 & 6 & 21 & $3.8 \pm 0.3$ \\
H6 & 6 & 20 & $1.8 \pm 0.2$ \\
\hline
\end{tabular}




\subsection{Thermal conductivity}

Thermal conductivity properties were assessed on three $150 \times 150 \times 50 \mathrm{~mm}^{3}$ rectangular prisms for each composition. The measurements were carried out with an EP500 guarded hot plate apparatus according to the standards ISO 8302 [35] and EN 12667 [36]. Before testing, the specimens were dried at $100^{\circ} \mathrm{C}$ and placed in a desiccator to cool. They were wrapped in a thin plastic film to avoid any humidity uptake during the measurement. The test was performed at $25^{\circ} \mathrm{C}$ with a difference of temperature $(\Delta \mathrm{T})$ of $10^{\circ} \mathrm{C}$ between the two plates. Steady state was assumed to have been reached when the change in conductivity was less than $1 \%$ in 60 minutes. To calculate the thermal conductivity $(\lambda)$, one-dimensional heat transfer by steady state conduction was assumed (1):

$$
\lambda=\frac{Q \cdot e}{\Delta T \cdot S}
$$

where $Q$ is the heat input $(\mathrm{W})$, e the thickness of the specimen $(\mathrm{m})$, and $\mathrm{S}$ its cross section $\left(m^{2}\right)$.

\subsection{Specific heat capacity}

Specific heat capacity $\left(c_{p}\right)$ characterizes the ability of a material to store thermal energy. This value was assessed on two samples of each component of the composite materials (FWAS, Straw, Hemp shiv and Corn Cob) through Differential Scanning Calorimetry (DSC). In this study, the device used was a NETZSCH STA 449 F3 and the measurement was performed on the basis of NF EN ISO 11357-4 [37]. Prior to be tested, the samples were dried at $50^{\circ} \mathrm{C}$ until stabilization of the mass before being cooled in a desiccator. The measurements were done with a temperature increasing from $30^{\circ} \mathrm{C}$ to $70^{\circ} \mathrm{C}$ applying the method detailed in [38].

\subsection{Water vapour permeability}


Measurements were realized on three cylindrical specimens $5 \mathrm{~cm}$ in diameter and $5 \mathrm{~cm}$ high (Ф5H5) for each composition. The wet cup method was applied according to standard NF EN ISO 12572 [39]. The wet cup was chosen to highlight the effects of capillary transfer in an earth material. Water vapour and liquid transfers occurred simultaneously through the sample during the wet cup test. The assessed property thus corresponded to an apparent water vapour permeability. Before testing, specimens were kept at $20^{\circ} \mathrm{C}$ and $50 \% \mathrm{RH}$. The humidity of the wet cup was regulated at $86 \%$ by means of a saturated salt solution of potassium chloride. This cup, with the specimen on its top, was placed in a chamber regulated at $23^{\circ} \mathrm{C}$ and $50 \% \mathrm{RH}$. The gradient of relative humidity created an outgoing flow of water vapour. The specimens were surrounded by an adhesive waterproof aluminium tape on the lateral face. They were then placed on a plastic support to avoid contact with the saline solution. The whole setup was finally sealed by a mix of $60 \%$ beeswax and $40 \%$ paraffin. The arrangements were weighed regularly until a steady-state vapour flux was established. The transmission rate of water vapour through the sample ( $G$ in $\mathrm{kg}^{-\mathrm{s}^{-1}}$ ) was determined by linear regression excluding the initial, non-linear, phase.

The water vapour permeability $(\delta)$ and the water vapour diffusion resistance factor $(\mu)$ were then determined for the seven compositions. The water vapour permeability $\left(\mathrm{kg} \cdot \mathrm{m}^{-1} \cdot \mathrm{s}^{-1} \cdot \mathrm{Pa}^{-1}\right)$ was calculated with the following equation (2) which takes the resistance of the air-layer between the base of the sample and the saturated salt solution into account [38]:

$$
\delta=\frac{e}{\frac{A . \Delta \mathrm{p}}{G}-\frac{e_{a}}{\delta_{a}}}
$$

with e $(\mathrm{m})$ the thickness of the sample, $A\left(\mathrm{~m}^{2}\right)$ the exposed surface area of the sample, $\Delta p$ $(\mathrm{Pa})$ the vapour pressure difference across the sample, $\mathrm{e}_{\mathrm{a}}(\mathrm{m})$ the thickness of the air layer between the sample and the salt solution and $\delta_{a}$ the water vapour permeability of the air $\left(\mathrm{kg} \cdot \mathrm{m}^{-1} \cdot \mathrm{s}^{-1} \cdot \mathrm{Pa}^{-1}\right)$.

The vapour pressure difference was calculated using equation (3) [39]:

$$
\Delta p=\left(R H_{2}-R H_{1}\right) \times 610.5 \times e^{\frac{17.269 \times \theta}{237.3+\theta}}
$$


with $\mathrm{RH}_{1}$ and $\mathrm{RH}_{2}(\%)$ the relative humidity inside and outside the cup, respectively, and $\theta$ the temperature $\left({ }^{\circ} \mathrm{C}\right)$.

The water vapour permeability of the air was determined using equation (4) [40]:

$$
\delta_{a}=\frac{2.3056 \times 10^{-5} \cdot p_{0}}{R \times T \times p}\left(\frac{T}{273}\right)^{1.81}
$$

with $\mathrm{p}_{0}=1013.25(\mathrm{hPa})$, the standard atmospheric pressure, $\mathrm{R}=462\left(\mathrm{~N} \cdot \mathrm{M} \cdot \mathrm{kg}^{-1} \cdot \mathrm{K}^{-1}\right)$ the gas constant for water vapour, $\mathrm{T}(\mathrm{K})$ the temperature and $\mathrm{p}(\mathrm{hPa})$ the atmospheric pressure.

The water vapour diffusion resistance factor was finally calculated with equation (5):

$$
\mu=\frac{\delta_{a}}{\delta}
$$

\subsection{Sorption and desorption isotherms}

The relation between the water content of a material and the relative humidity of the environment at constant temperature can be represented by its sorption-desorption isotherm. The sorption-desorption property is necessary to model the buffering effect of a material and has great influence on its resistance to the proliferation of micro-organisms [32].

\subsubsection{Saturated salt solution method}

The saturated salt solution method consists of exposing a material to various defined relative humidity levels regulated by saturated salt solutions at a constant temperature. The water content of the material is then determined gravimetrically. The detailed experimental procedure is presented in the standard NF EN ISO 12571 [27]. The samples were exposed to six conditions controlled by six different salts. Their theoretical values of relative humidity and the associated uncertainties are presented in Table 3. The choice of the salts was made according to their availability in the laboratory and the recommendations of the standard, which requires at least five salt solutions in the range of $9 \%$ to $93 \%$ of relative humidity.

The test was assessed on some pieces of broken monolithic samples ( $55 \mathrm{H} 5$-specimens), of mass between 7 and $16 \mathrm{~g}$, and on loose particles (plant and earth), of mass between 0.5 and 
$5 \mathrm{~g}$. The masses differed depending on the bulk density of the material. Approximately the same volume was tested each time. The test was performed in triplicate. The samples were first dried at $50^{\circ} \mathrm{C}$, as done in [7], [29], until constant mass was reached (weight variation of less than $0.1 \%$ between two weighings $24 \mathrm{~h}$ apart). The samples were then put in a sealed ventilated box to be successively exposed to the different relative humidity steps. The relative humidity was increased in steps from around $8 \%$ to $95 \%$ to determine the sorption curve. It was then decreased from $94 \%$ to $8 \%$ in order to trace the desorption curve. The moisture content was calculated at equilibrium, when the mass variation was less than $0.1 \%$ between three consecutive weighings.

Table 3. Equilibrium relative humidity of the different saturated salt solutions at $20^{\circ} \mathrm{C}$

\begin{tabular}{cc}
\hline Relative humidity (\%) & Salt \\
\hline $7.98 \pm 1.9^{1}$ & Sodium hydroxide $(\mathrm{NaOH})$ \\
$22.51 \pm 0.32^{1}$ & Potassium acetate $\left(\mathrm{CH}_{3} \mathrm{COOK}\right)$ \\
$43.16 \pm 0.33^{1}$ & Potassium carbonate $\left(\mathrm{K}_{2} \mathrm{CO}_{3}\right)$ \\
$65.5^{2}$ & Ammonium nitrate $\left(\mathrm{NH}_{4} \mathrm{NO}_{3}\right)$ \\
$75.47 \pm 0.14^{1}$ & Sodium chloride $(\mathrm{NaCl})$ \\
$94.62 \pm 0.66^{1}$ & Potassium nitrate $\left(\mathrm{KNO}_{3}\right)$ \\
\hline
\end{tabular}

\footnotetext{
${ }^{1}$ According to NF EN ISO 12571 [27]

${ }^{2}$ According to Winston and Bates [41]
}

\subsubsection{DVS method}

The sorption-desorption isotherms of the different materials were also evaluated by the Dynamic Vapour Sorption (DVS) method. Temperature and relative humidity are the two parameters regulated by the device (Surface Measurement Systems, London, UK). The RH inside the hermetic cell is regulated by means of a dry gas (nitrogen). The schematic system is represented in Figure 1. The specimen, suspended by a micro-balance, was weighed 
every 60 seconds. The test was assessed on monolithic broken samples ( $\$ 5 \mathrm{H} 5$-specimens), of mass between 0.4 and $1.4 \mathrm{~g}$, and on loose particles (plant and earth), of mass between 30 and $90 \mathrm{mg}$. The masses were very low because of the small sample holder volume (Figure 2). Two specimens of each formulation were tested and were assumed to be representative of these hygroscopic materials [4], [42].

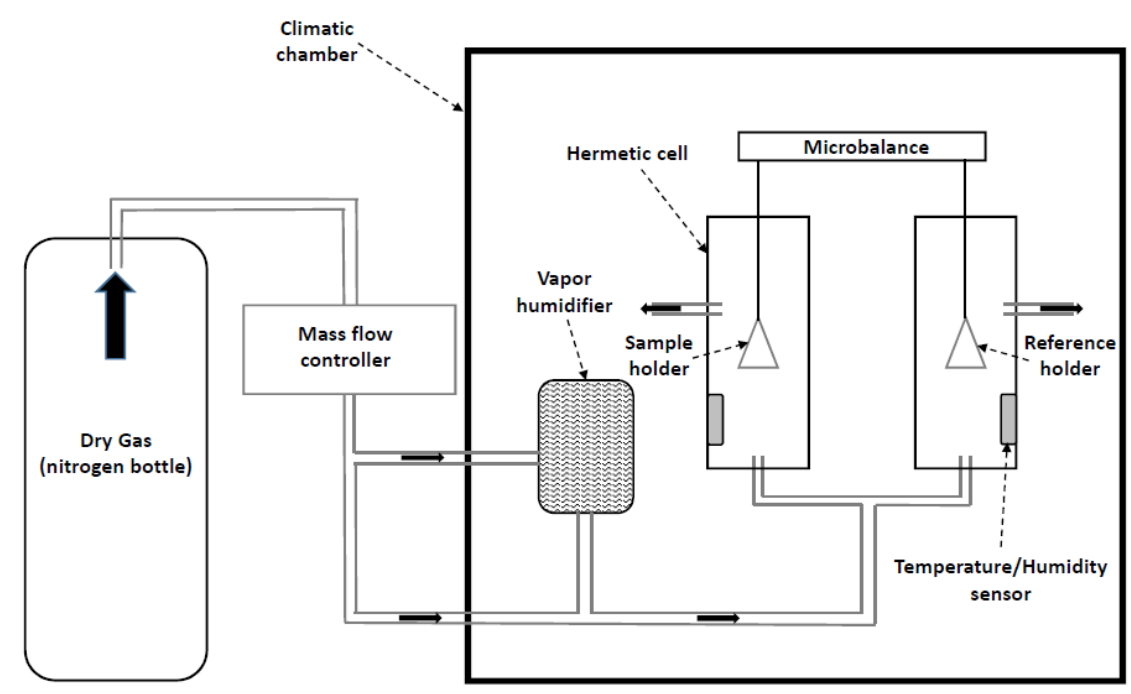

Figure 1. Schematic layout of the DVS system [7]

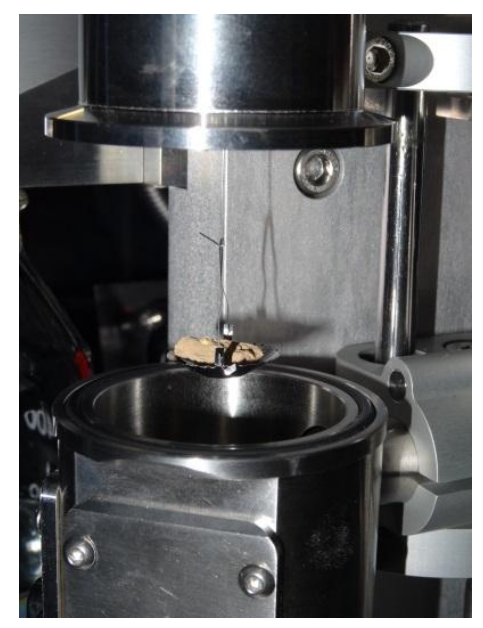

Figure 2.Sample holder in its opened cell (here CC3 sample)

Before testing, the specimen was dried at $50^{\circ} \mathrm{C}$ in the DVS device for $2 \mathrm{~h}$. The test was carried out at $23^{\circ} \mathrm{C}$, which is the same temperature as the one presented in the standard of the saturated salt solution method, EN NF ISO 12571 [27]. Relative humidity was regulated in successive stages from 0 to $95 \%$ by steps of $10 \% \mathrm{RH}$, except for the last stage, of $5 \% \mathrm{RH}$. 
For each step, moisture balance was considered to be reached in the specimen if the mass variation over the time variation $(\mathrm{dm} / \mathrm{dt})$ was less than $5.10^{-4} \% \cdot \mathrm{min}^{-1}$ over a ten-minute period [29] or in a maximum time interval of 360 minutes (twice this time for the last three steps). The water content was calculated as the ratio of the water contained in the material to the mass of the sample (weight over weight). Figure 3 is an example of sorption-desorption behaviour with this programme for an S6 specimen.

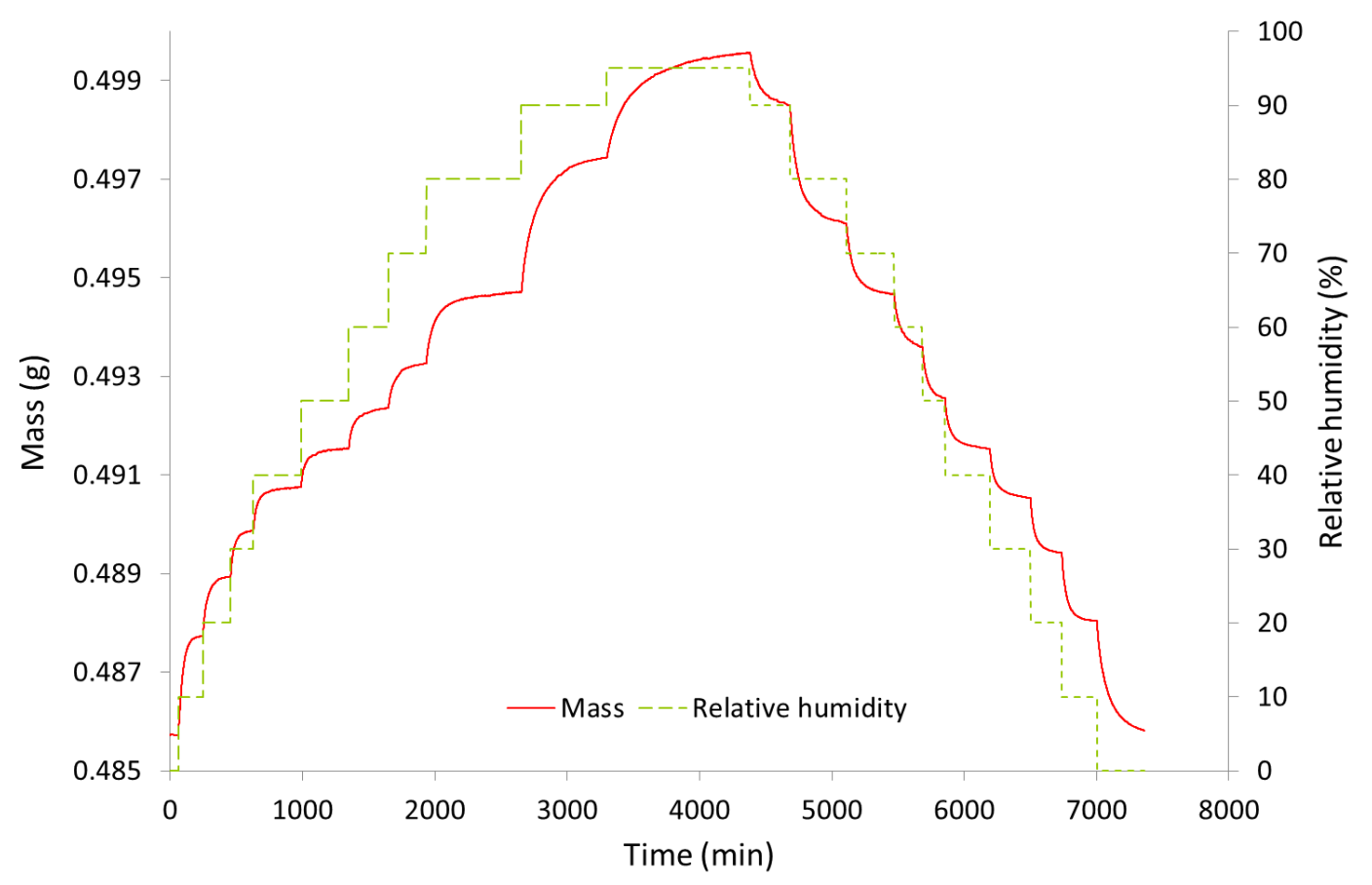

Figure 3. Typical variation of mass with relative humidity steps for the DVS (here sorption-desorption of an $\mathrm{S} 6$ specimen)

2.7. Prediction of the Moisture Buffer Value from the steady state properties This paper deals with the measurement of the steady-state hygrothermal properties of earthen materials. However, the moisture buffering capacity of this type of material is often asserted [43]. Thus, it was chosen to calculate a theoretical Moisture Buffer Value, called $\mathrm{MBV}_{\text {ideal, }}$, by means of calculations presented in the literature. A good correlation between the experimental and the theoretical values was found in [4]. The calculations were thus made with the equations proposed by the Nordtest report [11].

First, the moisture effusivity $b_{m}\left(\mathrm{~kg} \cdot \mathrm{m}^{-2} \cdot \mathrm{Pa}^{-1} \cdot \mathrm{s}^{-1 / 2}\right)$ was determined with equation (6): 


$$
b_{m}=\sqrt{\frac{\delta \cdot \rho_{d} \cdot \xi}{p_{s a t}}}
$$

with $\delta\left(\mathrm{kg} \cdot \mathrm{m}^{-1} \cdot \mathrm{s}^{-1} \cdot \mathrm{Pa}^{-1}\right)$ the water vapour permeability measured with the wet cup, $\rho_{d}\left(\mathrm{~kg} \cdot \mathrm{m}^{-3}\right)$ the dry density, $p_{\text {sat }}(\mathrm{Pa})$ the water vapour saturation pressure at $\theta=23^{\circ} \mathrm{C}$, and $\xi$ the moisture capacity $\left(\mathrm{kg} \mathrm{kg}^{-1}\right)$. The water vapour saturation pressure was calculated with equation (7):

$$
p_{\text {sat }}=610 \cdot 5 \cdot e^{\left(\frac{17 \cdot 269 . \theta}{237.3+\theta}\right)}
$$

The moisture capacity was calculated from the results of the sorption experiment (with SSS and DVS). It corresponds to the slope of the sorption curve between 33 and $75 \%$, which is assumed linear, calculated according to equation (8) using a linear correlation:

$$
\xi=\frac{\partial u}{\partial \phi}
$$

with $\mathrm{u}\left(\mathrm{kg} \cdot \mathrm{kg}^{-1}\right)$ the moisture content and $\Phi$ (without unit) the $\mathrm{RH}$.

The $\mathrm{MBV}_{\text {ideal }}$ was finally calculated from equation (9), relative to $8 \mathrm{~h} / 16 \mathrm{~h}$ cycles:

$$
M B V_{\text {ideal }}=0.00568 \cdot p_{\text {sat }} \cdot b_{m} \cdot \sqrt{t_{p}}
$$

where $t_{p}(s)$ is the time period, corresponding to $24 \mathrm{~h}$.

\section{RESULTS AND DISCUSSION}

3.1. Thermal conductivity

As has been widely reported in the literature, the main interest of adding a bio-resource in an earth matrix is to improve the thermal insulation behaviour of the material [8], [13], [44]. The thermal conductivity of the seven materials was measured on three samples of each formulation, in a dried state. The effect of the plant aggregate content on thermal conductivity is shown in Figure 4. 


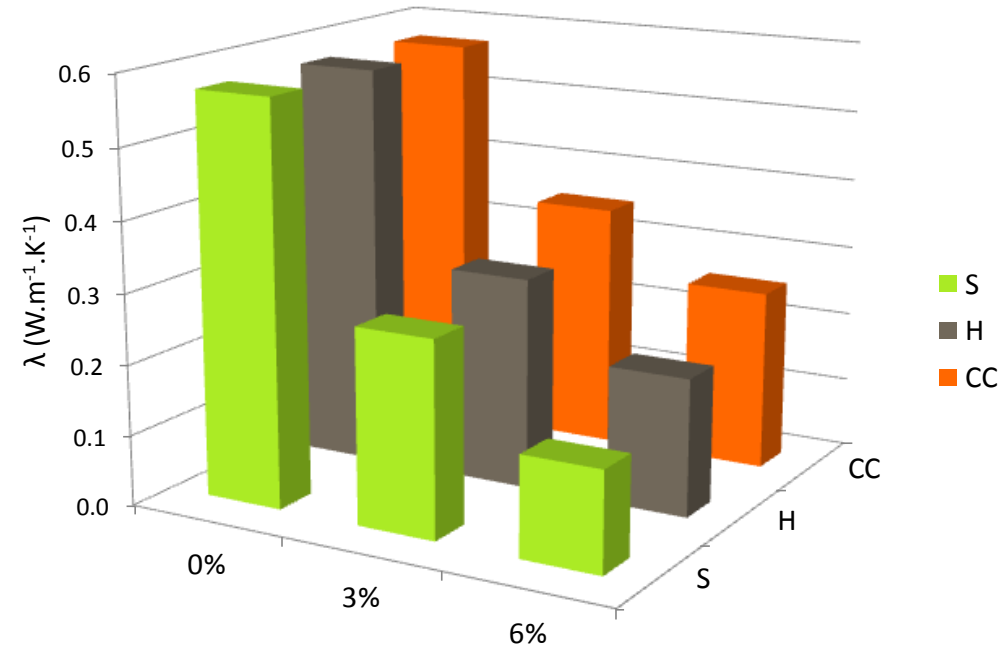

Figure 4. Thermal conductivity of the different materials

Thermal conductivity of the specimens made without any plant aggregate (FWAS) is 0.57 $\mathrm{W} \cdot \mathrm{m}^{-1} \cdot \mathrm{K}^{-1}$. For the specimens with plant aggregates, the values of thermal conductivity range from $0.14 \mathrm{~W} \cdot \mathrm{m}^{-1} \cdot \mathrm{K}^{-1}$ for S6 specimens to $0.35 \mathrm{~W} \cdot \mathrm{m}^{-1} \cdot \mathrm{K}^{-1}$ for CC3 specimens. These results show that an addition of plant aggregates in an earth matrix decreases the thermal conductivity of the material. The most efficient plant aggregate for improving the thermal insulation of the material seems to be straw. The addition of $6 \%$ of straw decreased the thermal conductivity by $75 \%$ in comparison with an FWAS specimen whereas the decrease was only $55 \%$ in the case of an addition of $6 \%$ of corn cob. This is in accordance with previous results on the bulk density of plant aggregates (Table 1) and of the composites tested here (Table 4).

Although a constant mass proportion of the different plant aggregates was used in the manufacture of the material, the resulting volume proportion was different for each nature of plant aggregate. The volume proportion $(\mathrm{V})$ of the plant aggregates contained in the different composites can be calculated knowing the density of the FWAS specimen and the density and mass proportion of plant aggregate for each composite. The results are presented in Table 4 , together with the dry density $\left(\rho_{d}\right)$, the thermal conductivity $(\lambda)$ and the mass proportion (M) of the different mixes. 
Table 4. Physical description of the different formulations

\begin{tabular}{ccccc}
\hline Reference & $\boldsymbol{\rho}_{\mathrm{d}}\left(\mathrm{kg} \cdot \mathrm{m}^{-3}\right)$ & $\boldsymbol{\Lambda}\left(\mathbf{W} \cdot \mathbf{m}^{-1} \cdot \mathrm{K}^{-1}\right)$ & $\mathbf{M}$ (\%mass.) & $\mathbf{V}$ (\%vol.) \\
\hline FWAS & $1891 \pm 54$ & $0.57 \pm 0.03$ & 0 & 0 \\
S3 & $1537 \pm 5$ & $0.28 \pm 0.02$ & 3 & 21 \\
H3 & $1519 \pm 38$ & $0.30 \pm 0.01$ & 3 & 22 \\
CC3 & $1671 \pm 21$ & $0.35 \pm 0.02$ & 3 & 14 \\
S6 & $1100 \pm 49$ & $0.14 \pm 0.01$ & 6 & 45 \\
H6 & $1271 \pm 16$ & $0.20 \pm 0.01$ & 6 & 37 \\
CC6 & $1565 \pm 18$ & $0.26 \pm 0.01$ & 6 & 22 \\
\hline
\end{tabular}

The volume proportion difference is clear for the composites containing $6 \%$ of plant aggregates. There is indeed a volume of straw of $45 \%$ whereas the volume of hemp shiv is only $37 \%$ and corn cob only $22 \%$.

Concerning thermal properties, the higher the plant aggregate content is, the lower is the thermal conductivity. This can be explained by the associated decrease of bulk density due to the intra-granular porosity of the plant particle. Thermal conductivity values of the composites studied are plotted versus their dry density in Figure 5. Other values of earth materials with bio-aggregates, from the literature, have been added for comparison. All the values from the literature came from experiments, except for those of Laurent [45] and Al Rim et al. [12], which came from theoretical models. 


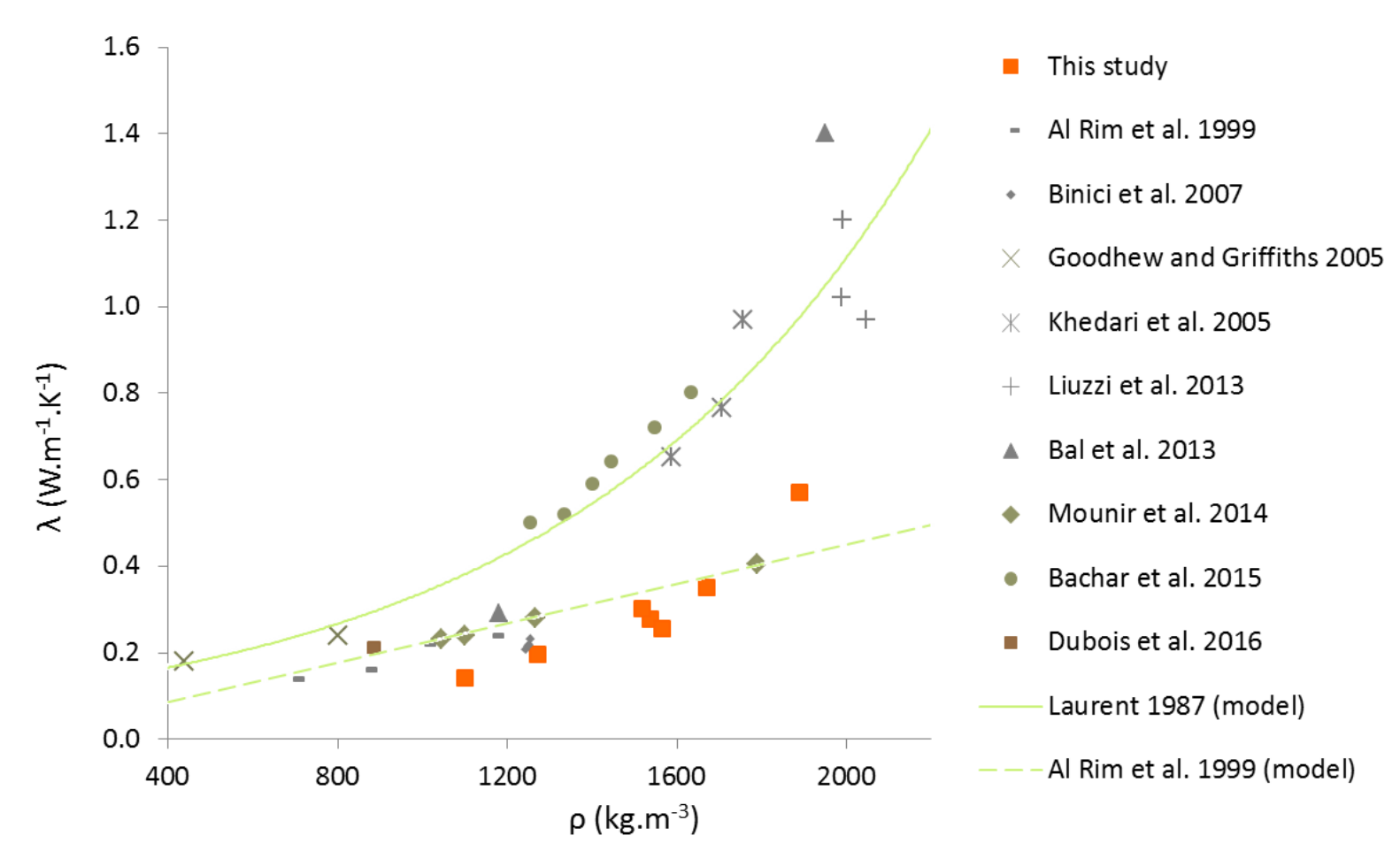

Figure 5. Comparison of thermal conductivity values found experimentally (in this study and in the literature) and theoretical values (from the literature) as a function of density

All the materials from the literature presented in Figure 5 are earth-based. They can be stabilized with lime [3], with plant particles such as coconut fibres [46] or straw [45], or with plant particles and cement [17]. Even though the results all came from the same type of material, the values present a large range of variation. For example, it can be seen on Figure 5 that, for a dry density of around $1500 \mathrm{~kg} \cdot \mathrm{m}^{-3}$, the thermal conductivity values range between $0.3 \mathrm{~W} \cdot \mathrm{m}^{-1} \cdot \mathrm{K}^{-1}$ (this study) and $0.7 \mathrm{~W} \cdot \mathrm{m}^{-1} \cdot \mathrm{K}^{-1}$ [44]. In the same way, for a dry density of around $2000 \mathrm{~kg} \cdot \mathrm{m}^{-3}$, the thermal conductivity values range between $0.6 \mathrm{~W} \cdot \mathrm{m}^{-1} \cdot \mathrm{K}^{-1}$ (this study) and $1.4 \mathrm{~W} \cdot \mathrm{m}^{-1} \cdot \mathrm{K}^{-1}[14]$. The measured values of the present study are thus situated in the lower part of the measured thermal conductivities. It can be observed that the values of the present study are of the same order of magnitude as [17], [47] and quite close to the values of [12], but significantly lower than the other references.

However, a correlation can be made between the thermal conductivity and the density of the materials. Several relations have already been developed. Laurent [45] has developed a relation for wattle and daub expressed as follows (10): 


$$
\lambda=0.103 \times 10^{0.517 \rho}
$$

A linear relation (11) was determined for clay-cement-wood composites by Al Rim et al. [12]:

$$
\lambda=0.228 \rho-0.006
$$

where, in both cases, $\lambda$ is the thermal conductivity of a material in the dry state and $\rho$ is the dry density.

These two relations, plotted on Figure 5, are quite different but seem to follow the two tendencies of the thermal conductivities. Laurent's relation gives a higher thermal conductivity than Al Rim's. The results of the present study are more correlated with Al Rim's.

\subsection{Specific heat capacity}

Typical specific heat capacity of the raw materials is presented in Figure 6. It can be observed that the specific heat capacity is linearly proportional with the temperature. The values are much higher for the plant particles, between around 1300 and $1600 \mathrm{~J} \cdot \mathrm{kg}^{-1} \cdot \mathrm{K}^{-1}$, than for the earth alone (between 800 and $900 \mathrm{~J} . \mathrm{kg}^{-1} . \mathrm{K}^{-1}$ ). However, some variations can be observed for the plant aggregates: straw has a specific heat capacity lower than hemp shiv and corn cob, which are close between each other. 


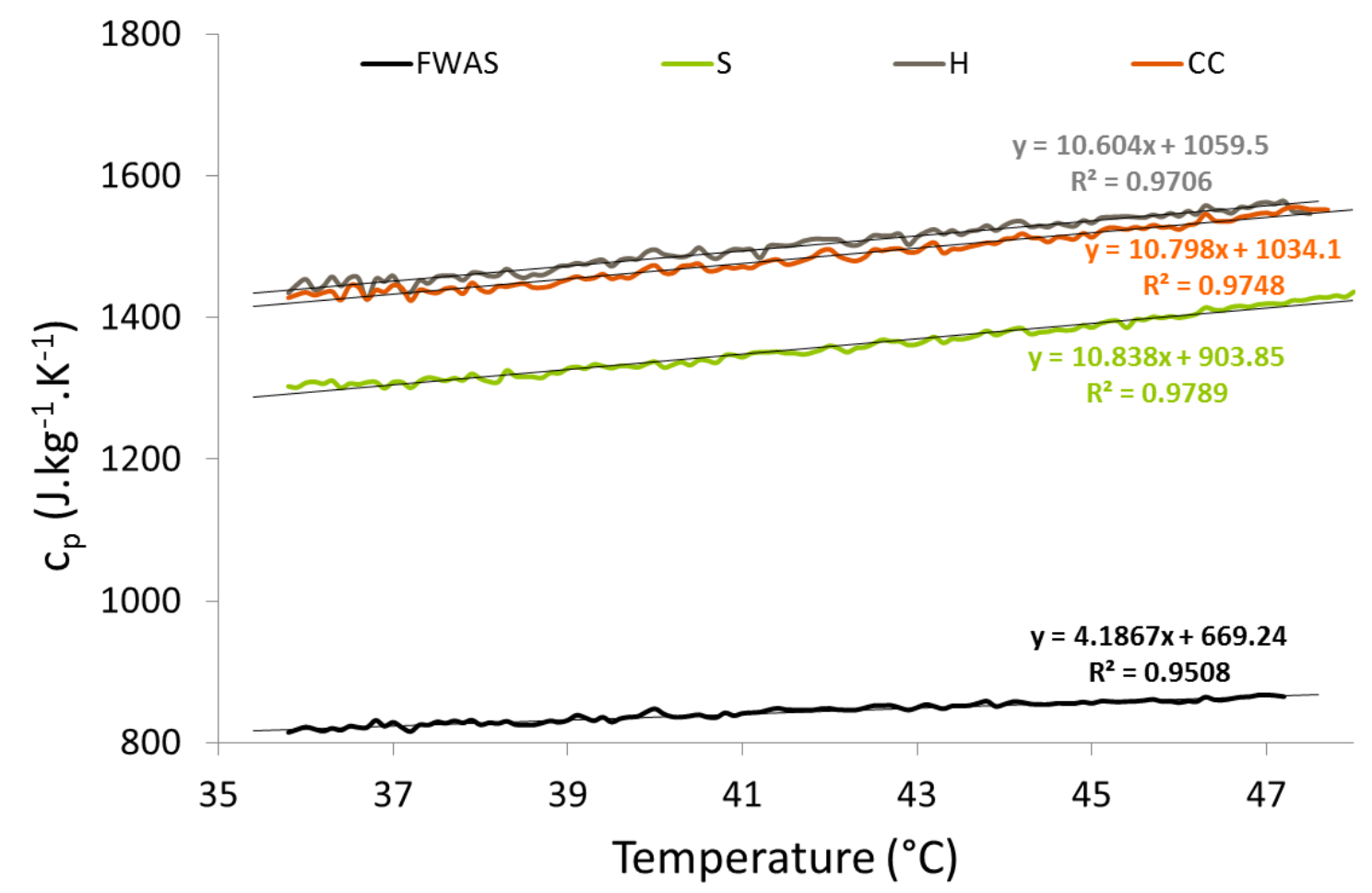

Figure 6. Specific heat capacity $\left(c_{p}\right)$ of the different raw materials as a function of temperature

Due to the method used, the temperature range of the measurement was above the ambient temperature. In order to deduce the specific heat capacity of the composite materials, the specific heat capacity is thus extrapolated at $25^{\circ} \mathrm{C}$, which is the same temperature as for the measurement of thermal conductivity. The obtained values are: 774, 1175, 1325 and 1304 $\mathrm{J} . \mathrm{kg}^{-1} . \mathrm{K}^{-1}$ for FWAS, straw, hemp shiv and corn cob respectively.

The specific heat capacity of the composite materials is then calculated with equation (12):

$$
c_{p, \text { composite }}=x_{F W A S} \cdot c_{p, F W A S}+x_{\text {aggregate }} \cdot c_{p, \text { aggregate }}
$$

where $\mathrm{x}$ is the proportion by mass of the various composite components (earth or plant aggregates).

In addition to the specific heat capacity $c_{p}$, various parameters could be calculated in order to assess the contribution of a material to the building thermal inertia, the most common being thermal effusivity and diffusivity [23], [24], [48]-[50]. 
These two parameters can be respectively calculated following equation (13) and equation (14) from thermal conductivity $(\lambda)$, dry density $\left(\rho_{d}\right)$ and specific heat capacity $\left(c_{p}\right)$ of the considered material.

$$
\begin{gathered}
E=\sqrt{\lambda \cdot \rho_{d} \cdot c_{p}} \\
D=\frac{\lambda}{\rho_{d} \cdot c_{p}}
\end{gathered}
$$

The resulting values are recapitulated in Table 5 for FWAS and the different composite formulations.

Table 5. Specific heat capacity $\left(c_{p}\right)$, volumetric heat capacity $\left(\rho_{d} \cdot c_{p}\right)$, calculated effusivity $(E)$ and calculated diffusivity (D) of the earth matrix and of the composite materials

\begin{tabular}{ccccc}
\hline & $\mathrm{c}_{\mathrm{p}}\left(\mathrm{J} \cdot \mathrm{kg}^{-1} \cdot \mathrm{K}^{-1}\right)$ & $\rho_{\mathrm{d}} \cdot \mathrm{c}_{\mathrm{p}}\left(\mathrm{J} \cdot \mathrm{m}^{-3} \cdot \mathrm{K}^{-1}\right)$ & $\mathrm{E}\left(\mathrm{J} \cdot \mathrm{K}^{-1} \cdot \mathrm{m}^{-2} \cdot \mathrm{s}^{-1 / 2}\right)$ & $\mathrm{D} \times \mathbf{1 0}^{-7}\left(\mathrm{~m}^{2} \cdot \mathrm{s}^{-1}\right)$ \\
\hline FWAS & 774 & 1463634 & 913 & 3.9 \\
S3 & 786 & 1208700 & 582 & 2.3 \\
H3 & 791 & 1201592 & 600 & 2.5 \\
CC3 & 790 & 1320745 & 680 & 2.7 \\
S6 & 800 & 879555 & 351 & 1.6 \\
H6 & 809 & 1028455 & 454 & 1.9 \\
CC6 & 808 & 1264254 & 573 & 2.1 \\
\hline
\end{tabular}

$c_{p}$ value for FWAS is lower than measurements reported in the literature on compressed stabilized earth bricks ranging from 939 to $1170 \mathrm{~J} . \mathrm{kg}^{-1} \cdot \mathrm{K}^{-1}$ [51], but slightly higher than those

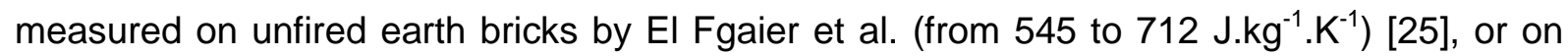
adobe by Abanto et al. (from 560 to $614 \mathrm{~J} \cdot \mathrm{kg}^{-1} \cdot \mathrm{K}^{-1}$ ) [26].

All the specific heat capacity values range between 770 and $810 \mathrm{~J}^{\mathrm{kg}} \mathrm{kg}^{-1} \cdot \mathrm{K}^{-1}$. Although the $\mathrm{c}_{\mathrm{p}}$ values of the plant aggregates are much higher than the $c_{p}$ of FWAS, the $c_{p}$ values of the 
composites are only slightly higher than earth material alone. This can be explained by the low mass content of the plant aggregates in comparison with the earth. Moreover, when volumetric heat capacity is considered, the incorporation of plant aggregates to the earth systematically limits this property due to the large decrease of density.

Despite the slight improvement observed on specific heat capacity, the addition of the plant aggregates engenders a decrease of the thermal effusivity values, from $913 \mathrm{~J} \cdot \mathrm{K}^{-1} \cdot \mathrm{m}^{-2} \cdot \mathrm{s}^{-1 / 2}$ in the case of FWAS material, until $351 \mathrm{~J} \cdot \mathrm{K}^{-1} \cdot \mathrm{m}^{-2} \cdot \mathrm{s}^{-1 / 2}$ in the case S6 specimens. The diffusivity is also affected by the introduction of plant aggregates, it decreases when the plant content increases. Once again, the lower value was obtained with the S6 mix.

Nevertheless the consequences of these evolutions on the thermal inertia of the envelope are contrasting. Indeed, to increase thermal inertia, materials should present low diffusivity and high effusivity [49]. A low diffusivity would lengthen the thermal delay existing between outdoor temperature change and indoor resulting temperature variation. A high effusivity would allow a quick absorption of heat by the material with limited surface temperature rise. These two distinct aspects of thermal inertia can be respectively qualified as inertia of transmission and inertia of storage [50].

So, plant aggregates incorporation into the unfired earth bricks would improve the transmission inertia of the wall but decrease its inertia of storage. These types of lightened earth based materials would then be more appropriated for the realisation of external walls delaying the heat transfer from outdoor to indoor.

\subsection{Water vapour permeability}

The water vapour permeability was measured for each formulation using the wet cup method. The assemblies were weighed daily. Using the measurements and the calculation presented in standard NF EN ISO 12572, the water vapour permeability $(\bar{\delta})$ and the water vapour diffusion resistance factor $(\mu)$ were deduced for each composite specimen. The average values calculated from the different formulations are presented in Table 6 . The water vapour diffusion resistance factor is generally used in comparisons. All the average 
water vapour diffusion resistance factors are close: between 4.8 and 7.0 . The values for earth alone (FWAS specimens) are similar to those of earth bricks studied by Cagnon et al. [29], for which $\mu$-values were between 3 and 7. They are slightly lower than other values of the literature, ranging between 5.5 and 8.2 (also measured with the wet cup) [4] or between 8 and $11[3]$.

The values for the bio-composites can be compared with the earth render containing oat fibres studied by Faria et al. [52], which was around 8 . They can also be compared with the water vapour permeability measured on cob (construction technique using earth with straw) by [5]. The $\mu$-values were between 6.5 and 9.8 . This result is quite close to the permeability of $\mathrm{S} 6$ and $\mathrm{H6}$, which were respectively 7.0 and 6.1 .

Table 6. Water vapour permeability of the materials

\begin{tabular}{|c|c|c|}
\hline Reference & $\begin{array}{c}\delta \times 10^{-11} \\
\left(\mathrm{~kg} \cdot \mathrm{m}^{-1} \cdot \mathrm{s}^{-1} \cdot \mathrm{Pa}^{-1}\right)\end{array}$ & $\mu$ \\
\hline FWAS & $4.0 \pm 0.3$ & $4.9 \pm 0.3$ \\
\hline S3 & $3.8 \pm 0.3$ & $5.2 \pm 0.4$ \\
\hline H3 & $4.1 \pm 0.5$ & $4.8 \pm 0.6$ \\
\hline CC3 & $3.8 \pm 0.5$ & $5.2 \pm 0.7$ \\
\hline S6 & $2.8 \pm 0.1$ & $7.0 \pm 0.3$ \\
\hline H6 & $3.2 \pm 0.1$ & $6.1 \pm 0.2$ \\
\hline CC6 & $3.9 \pm 0.5$ & $5.1 \pm 0.7$ \\
\hline
\end{tabular}




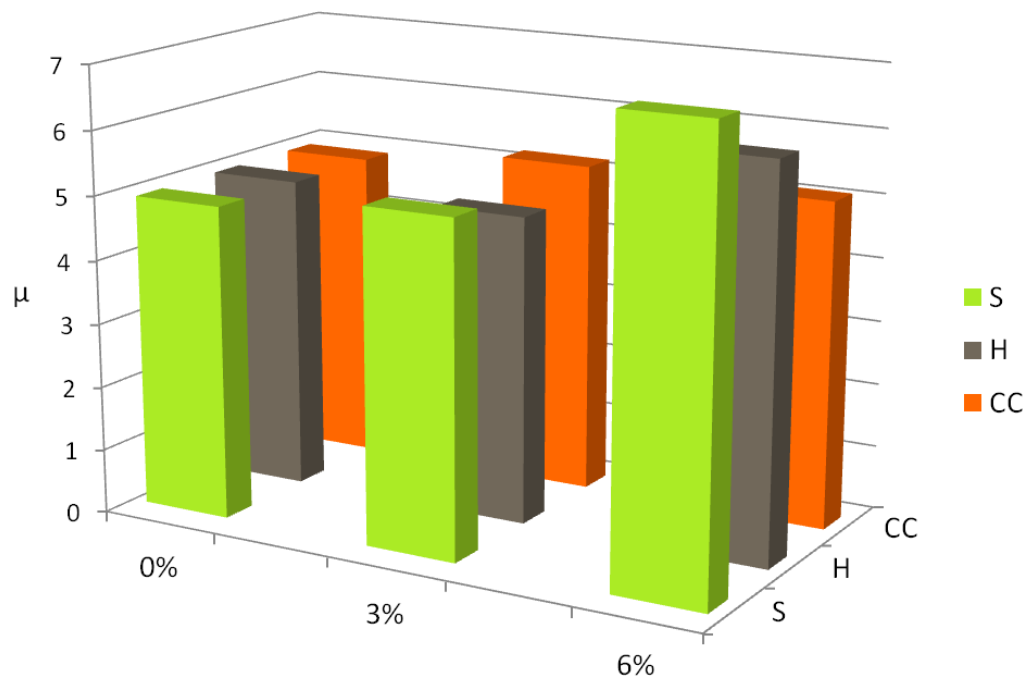

Figure 7. Water vapour diffusion resistance factor $(\mu)$ according to the plant aggregate content

The $\mu$-values are shown in Figure 7 . The results presented here do not bring out significant influence of the addition of $3 \%$ of plant aggregates on the permeability of the material. The same comment can be made about the composite including $6 \%$ of corn cob. In contrast, when the mixes with $6 \%$ of straw or hemp shiv are considered, an increase of $\mu$ is observed. Thus, even though the S6 and $\mathrm{H} 6$ composites present lower density due to the macroporosity of the plant aggregates, their apparent water vapour permeability is limited in comparison with the FWAS specimen. Liquid transfer in smaller pores has a major impact on the macroscopic water transport in clay material as shown by Fouchal et al. [9]. Their study on extruded earth bricks underlines the fact that, from $50 \% \mathrm{RH}$, capillary condensation occurs in the pores that are smaller than $0.1 \mu \mathrm{m}$ [9]; another study set a limit at $50 \mathrm{~nm}$ [53]. Moreover, it has also been shown that the intra-aggregate pore size in an earth material compacted to the Proctor density is between 10 and $50 \mathrm{~nm}$ [54].

The decrease of water vapour permeability in wet conditions due to the inclusion of straw or hemp shiv could then be explained by the reduction of capillary diffusion within the earth matrix. Indeed, the large volume content of these two plant aggregates (see Table 4) reduces the connectivity of the capillary porous network in comparison with FWAS or corn 
cob samples. This is consistent with the results of Fouchal et al. [9] showing that an earth material was more permeable than wood. Moreover on clay brick, a $\mu$-value in dry conditions was found to be 1.5 to 3.8 times greater than in wet conditions [29].

Considering the water vapour permeability, the inclusion of plant particles in an earth matrix does not seem beneficial. Nonetheless, the present results underline once again the large water vapour permeability of earth brick in comparison with the reference values of other load bearing building materials according to the 2012 French Thermal Regulations [55]. The permeability of earth bricks is comparable to that of porous construction materials such as wood concrete or gypsum (lower than 10) [29].

\subsection{Sorption isotherms}

\subsubsection{Saturated salt solution method}

The saturated salt solution (SSS) method is very time consuming. Three to four weighings per week were performed for around one year for all the sorption-desorption steps. Equilibrium needs to be reached at the end of a given $\mathrm{RH}$. However, the equilibrium was not completely reached at $94 \%$ of $\mathrm{RH}$ because of potential microbial growth [7]. During a preliminary test, mould growth was observed on the plant aggregates after two weeks at this step. The exposure to this last stage was thus stopped after two weeks, even if equilibrium was not reached.

\section{Bulk materials}

The sorption-desorption isotherm curves of the bulk materials are presented in Figure 8. The water content represented in the graph corresponds to a mass percentage (ratio of the mass of water to the mass of material). As already noted by other authors [5], [32], [56] for biobased materials, the curves presented here have a sigmoidal shape. According to the IUPAC classification [57], which determines six types of curves, these curves belong to Type II. There is a strong increase in water content at high $\mathrm{RH}$ because this is the zone of the curve 
where capillary condensation occurs [29], [57]. The curve is close to a vertical asymptote and the representativeness can thus be questionable at these $\mathrm{RH}$.

In Figure 8, similar behaviour can be noted between the three plant aggregates up to $75 \%$, although the sorption capacity of the straw is slightly higher than the other two in this range. At $94 \% \mathrm{RH}$, the corn cob has a moisture content that is slightly higher than that of the straw and much higher than that of hemp shiv. However, with the high standard deviations at $94 \%$ (particularly for the straw), no significant difference can be highlighted between straw and corn cob. The water content of the plant aggregates at $94 \% \mathrm{RH}$ is thus between 21 and $26 \%$, whereas it is only around $2 \%$ for the powdered FWAS. To compare with other natural fibres, at $60 \% \mathrm{RH}$ for example, the three plant aggregates have a water content of approximately 8.5\%. At the same $\mathrm{RH}$, the natural fibres tested by Hill et al. [28] presented quite a similar sorption capacity, between 7.5 and $10 \%$ for flax, coir, jute, Sitka spruce or hemp fibres, the exception being cotton fibres, which showed a lower sorption of $5.5 \%$. According to their conclusions, the sorption capacity increases with the $\mathrm{OH}$ accessibility and the lignin content of the fibres.

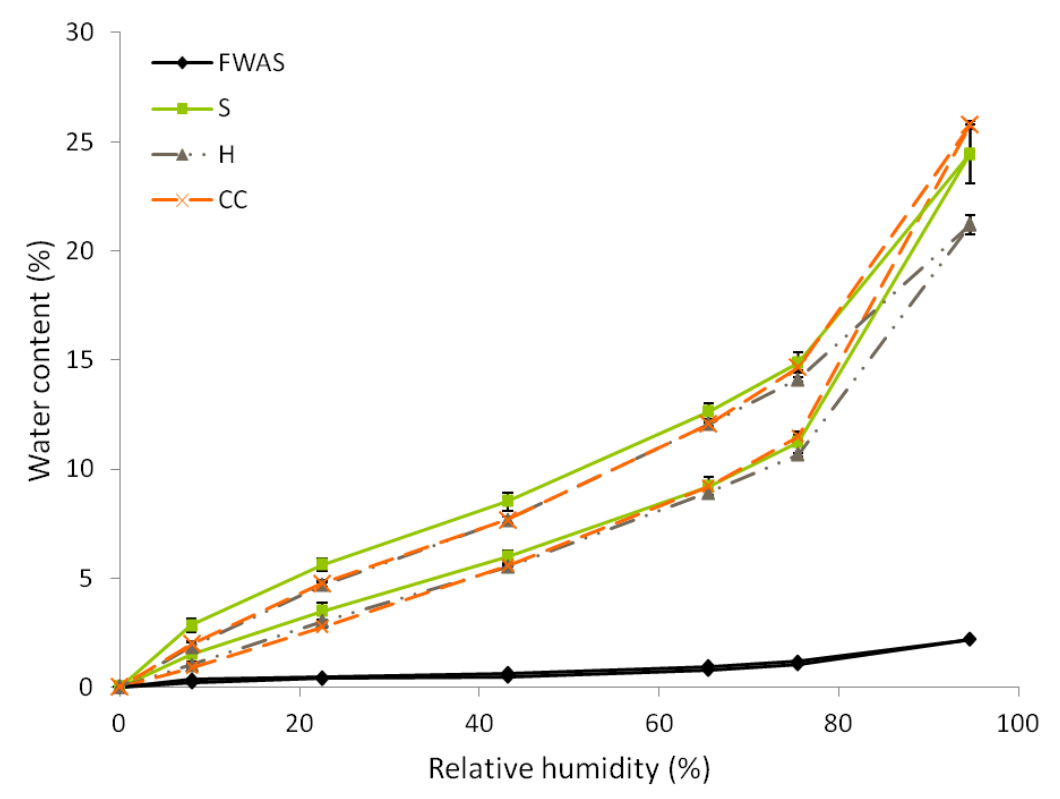

Figure 8. Sorption-desorption isotherms (at $20^{\circ} \mathrm{C}$ ) of the bulk materials 
The hysteresis is calculated by subtracting the water content of the sample during the drying isotherm from the water content during the wetting isotherm. This is a typical phenomenon for cellulosic and lignocellulosic materials and is explained by the ink-bottle effect (interconnected pore spaces) [5], [56]. The hysteresis values of the different raw materials are presented in Figure 9. For the three plant aggregates, it can be observed that the hysteresis value increases with the $\mathrm{RH}$. This is also the case for FWAS between 22 and $65 \%$. The values are much higher for the plant aggregates (between 1 and $3.5 \%$ ) than for the earth (lower than $0.2 \%$ ). According to Hill et al. [28], this result was to be expected because the hysteresis is greater for materials with high lignin content than for materials with low or no lignin content.

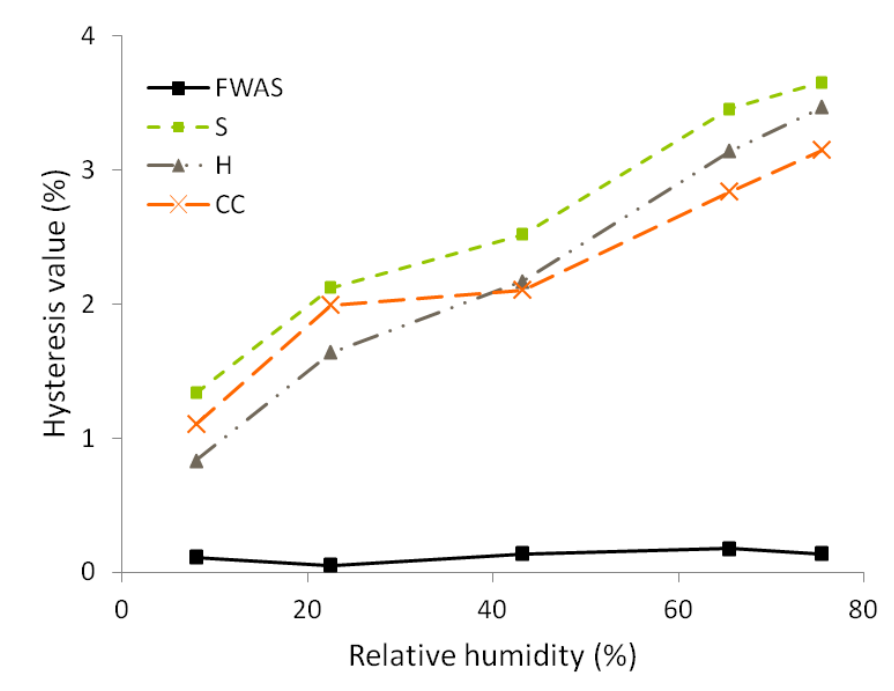

Figure 9. Isotherm hysteresis of the raw materials (SSS)

\section{Monolithic materials}

Composite and monolithic materials were also tested with the SSS method. Their sorptiondesorption isotherm curves are shown in Figure 10. In the same way as in the raw materials, the moisture content increases with relative humidity following the usual Type II curve [56].

The sorption capacity is higher in the case of an addition of $6 \%$ of plant aggregates than $3 \%$ or no addition (FWAS specimens). This is consistent with the moisture sorption capacity of bulk materials presented in Figure 8. Plant particles present higher porosity and their inclusion in an earth matrix consequently increases the moisture sorption capacity of the 
composites. There is no significant difference of sorption capacity for the same addition of content. As was seen with the sorption capacity of bulk plant aggregates, the type of plant does not have any real influence (Figure 8). At high $\mathrm{RH}$, the sorption capacity of FWAS specimens is $2.2 \%$. It is $2.7 \%$ and $3.2 \%$ on average for additions of $3 \%$ and $6 \%$ of plant aggregate, respectively. Consequently, an addition of $3 \%$ of plant aggregates increases the sorption capacity of the earth by about $21 \%$ and an addition of $6 \%$ increases it by about $46 \%$. The good sorption capacity of the plant particles improves the lower capacity of the earth, because of the increase in porosity [3]. However, it must be stressed that EMC was expressed in $\mathrm{kg}^{\mathrm{kg}}{ }^{-1}$ (Fig. 9). For a typical wall, made of the same volume of bricks, the difference of adsorption between the various mixes would be less marked since the density of the mixes including the plant aggregates would be reduced in comparison with the FWAS alone.

When compared with the literature results, the sorption capacity of FWAS is similar to the one found by Ashour et al. [58] for an earth plaster (EMC of $1.8 \%$ at $95 \% \mathrm{RH}$ ), but differs from other literature values. Cagnon et al. [29] assessed the sorption capacity of five unfired bricks, whose water content was between 4 and $5.5 \%$ at high RH. McGregor et al. [4] also studied a clay material and found an EMC of $4 \%$ at around $95 \% \mathrm{RH}$. The water sorption of cob was assessed in [5]. The water content was around 5.5\% at high $\mathrm{RH}$, but the straw content is unknown. In the case of a straw-clay mixture [59], where the straw content was very high in comparison to the clay content, the water content was around $12 \%$ at $93 \% \mathrm{RH}$. Thus, the sorption capacity of the FWAS seems to be lower than that of the earth reviewed. A link has been made between the sorption capacity and the nature of the clay mineral to explain that difference. Kaolinite seems less reactive than montmorillonite or illite [3], [29], [60]. Moreover, the clay content of the FWAS is low $(<20 \%)$ compared to the calcite content. 

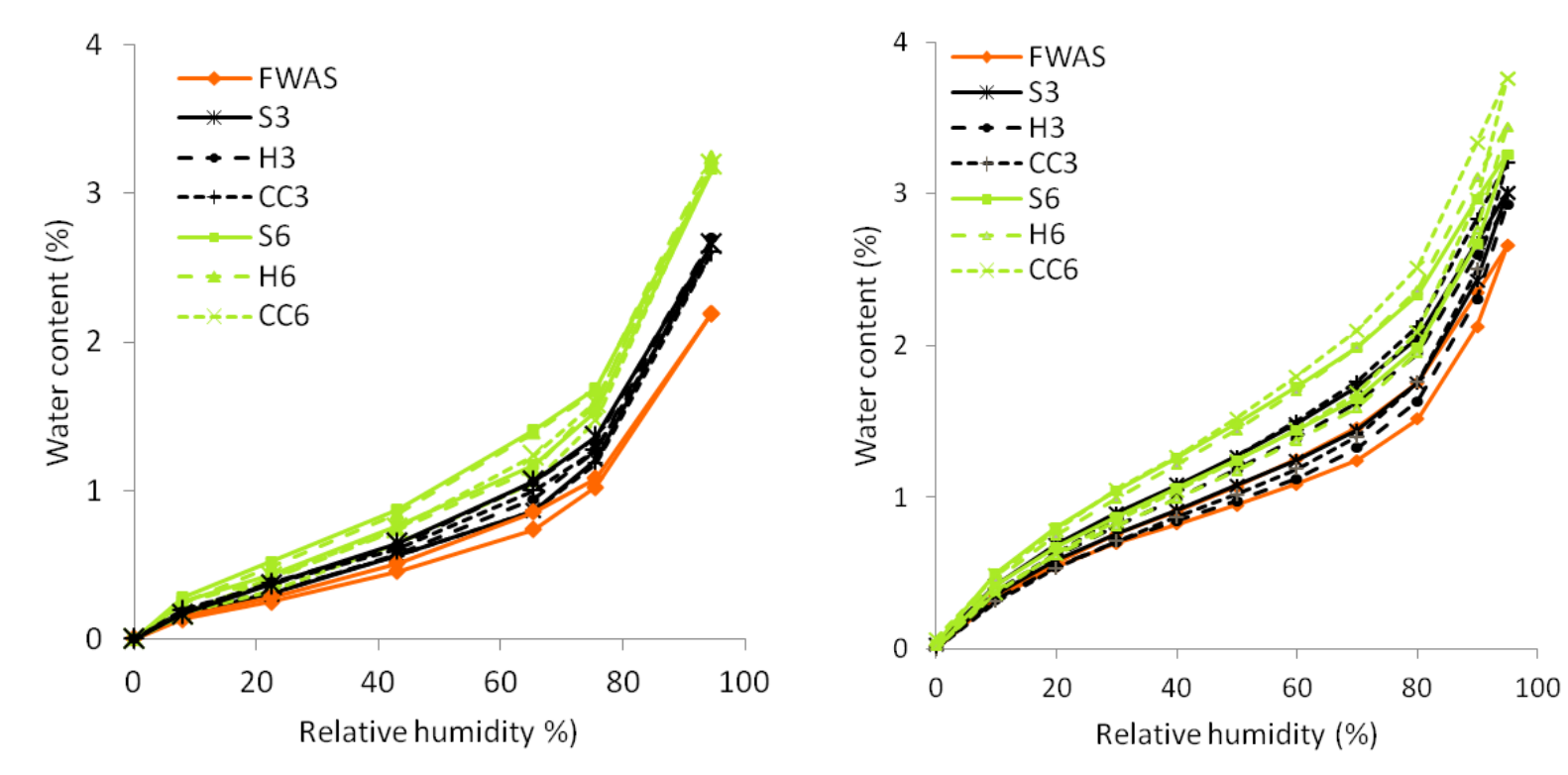

Figure 10. Sorption-desorption isotherms of all the formulations (SSS left, DVS right)

The isotherm hysteresis of each material is shown in Figure 11. For all the materials, the hysteresis value increases with the $\mathrm{RH}$ (except for the last point at around $75 \%$ ). The hysteresis of earth is the lowest while the hysteresis of composite materials with straw is one of the highest. The values are lower than in Cagnon et al. [29] where the hysteresis values can reach $0.7 \%$. In comparison, the hysteresis values of concrete are much greater [61], around $7 \%$. In the case of hemp concrete, hysteresis values ranged between 1 and 5\% [10], which is an expected result because hemp concrete contains more lignocellulosic materials than the composites of the present study. 


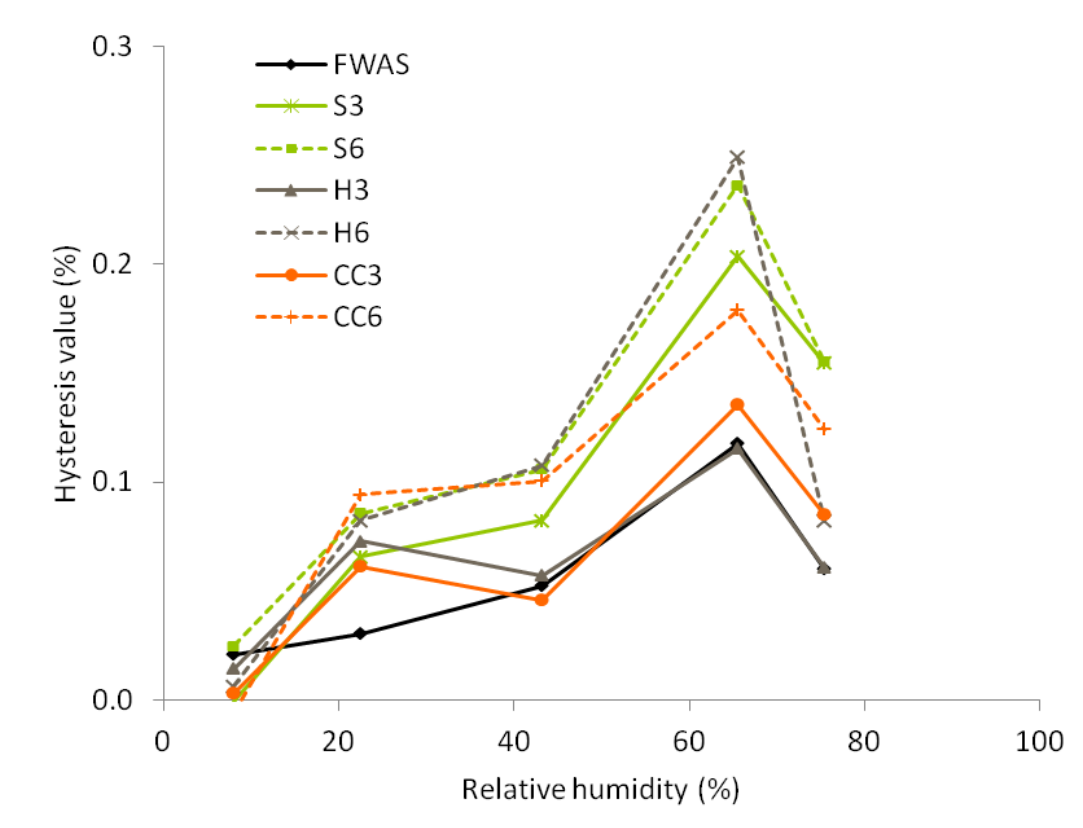

Figure 11. Isotherm hysteresis of the monolithic materials (SSS)

The sorption-desorption curves of powdered samples and monolithic samples of FWAS are compared in Figure 12. At low $\mathrm{RH}$, the bulk sample presents a higher sorption capacity than the monolithic sample. However from $50 \% \mathrm{RH}$, the two curves are very similar, with the same water content at $94 \% \mathrm{RH}$. This difference at low $\mathrm{RH}$ might be due to the difference of specific surface area. For powdered samples, the surface area available for monomolecular layer sorption is larger than for monolithic samples.

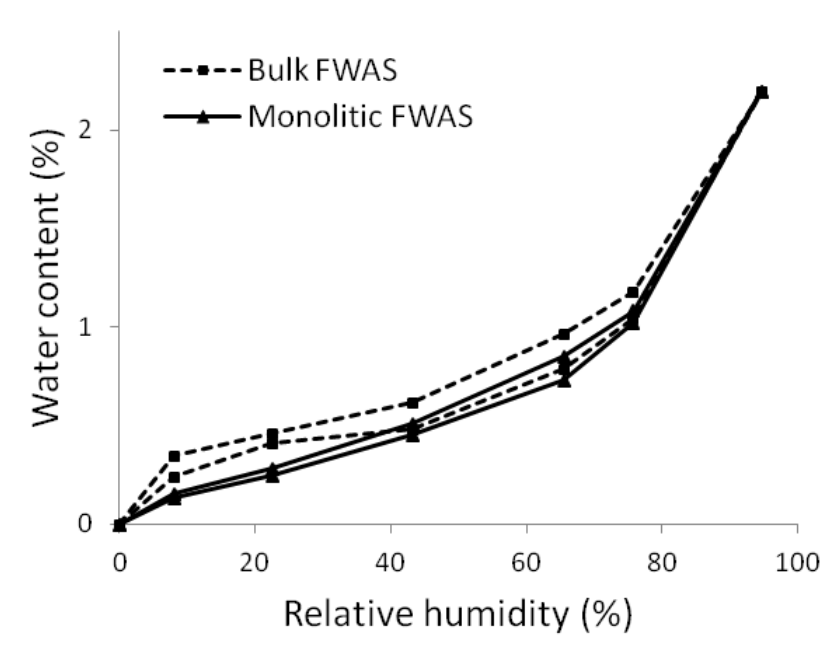

Figure 12. Sorption-desorption isotherms (SSS) of bulk and monolithic FWAS samples 
It should be noted that the SSS method can present some uncertainties in the regulation of $\mathrm{RH}$. The saturated salt solutions are highly sensitive to small variations of temperature. For example, a rapid increase from $20^{\circ} \mathrm{C}$ to $21^{\circ} \mathrm{C}$ can cause a drop of an $\mathrm{NaCl}$ solution from $75 \%$ to $71 \%$ [62]. The test was carried out in an air-conditioned room, but small variations of temperature could occur depending on the outside climate or the presence of people in the room.

\subsubsection{DVS method}

The test lasted about 7 days for each sample. Two samples per formulation were tested and the total duration was thus about 100 days. The results of the DVS sorption-desorption isotherm curves for monolithic samples are shown in Figure 10. The results, quite similar to those obtained with the SSS method, are not commented in detail.

For the sake of clarity, the standard deviations of the tests are not represented. However, the standard deviation of S6 specimens was very large. With the small volume of the sample tested and the heterogeneity of the composite material, there is obviously a problem of representativeness. In the case of CC3 and CC6 formulations, the samples were weighed to obtain a corn cob content of $3 \%$ or $6 \%$. Even if the samples were monolithic, the corn cob particles presented poor adhesion with the earth matrix, allowing separate weighing of the corn cob and the earth. The standard deviations of the composites with corn cob were thus lower than for the straw composites.

\subsubsection{Comparison between DVS and SSS methods}

The two methods to plot sorption-desorption isotherm curves can be compared. The curves were similar for the different materials, so only one is presented here for the bulk materials (S sample) and two materials for the monolithic samples (FWAS and a bio-composite, CC6) in Figure 13.

For each material, the curves obtained with the two techniques show a similar shape. It can, however, be observed that the sorption capacity is always higher when measured with the 
DVS technique. This observation was already made in [29], where it was compared for clay bricks and in [32] for the case of bio-based insulating materials. This difference was just slightly higher in [7] for barley straw. The difference between the two techniques was only of the same order of magnitude as the uncertainties. This can be explained by the definition of the dry state according to the method used. When dried in an oven, the sample can contain residual humidity [63] and its dry mass might be overestimated [7]. Thus the sorption capacity would seem lower with the SSS technique. Even if the initial samples did not have exactly the same moisture content, the loss of water during the drying was quite different according to the method used. For example, the loss of water was approximately $0.2 \%$ for a monolithic FWAS sample dried in the oven whereas it was around $0.8 \%$ in the case of drying with the DVS device.

A "correction" of the initial dry mass $M_{0}$ was applied in Figure $13(d)$ in order to evaluate the impact of a supposed overestimation of the dry mass with the SSS technique. With a decrease of $0.45 \%$ of the dry mass of the monolithic CC6 samples, the curves obtained with SSS and DVS methods are quite closely superposed. A significant difference remains for the point at $8 \% \mathrm{RH}$, which could be due to the duration of the test as the stabilization time with the SSS technique was much longer than with the DVS technique, especially for low $\mathrm{RH}$. Further tests will be performed in order to evaluate the impact of the stabilization criteria for the DVS technique on the EMC.

A difference of hysteresis can also be seen between the two methods. The hysteresis obtained with the DVS method is higher than that obtained with the SSS method. This might still be due to a kinetics issue: although the sample was bigger in the case of the SSS method, it was exposed to a certain $\mathrm{RH}$ for at least two weeks, against 6 hours (for $\mathrm{RH}$ lower than $70 \%$ ) with the DVS method. 

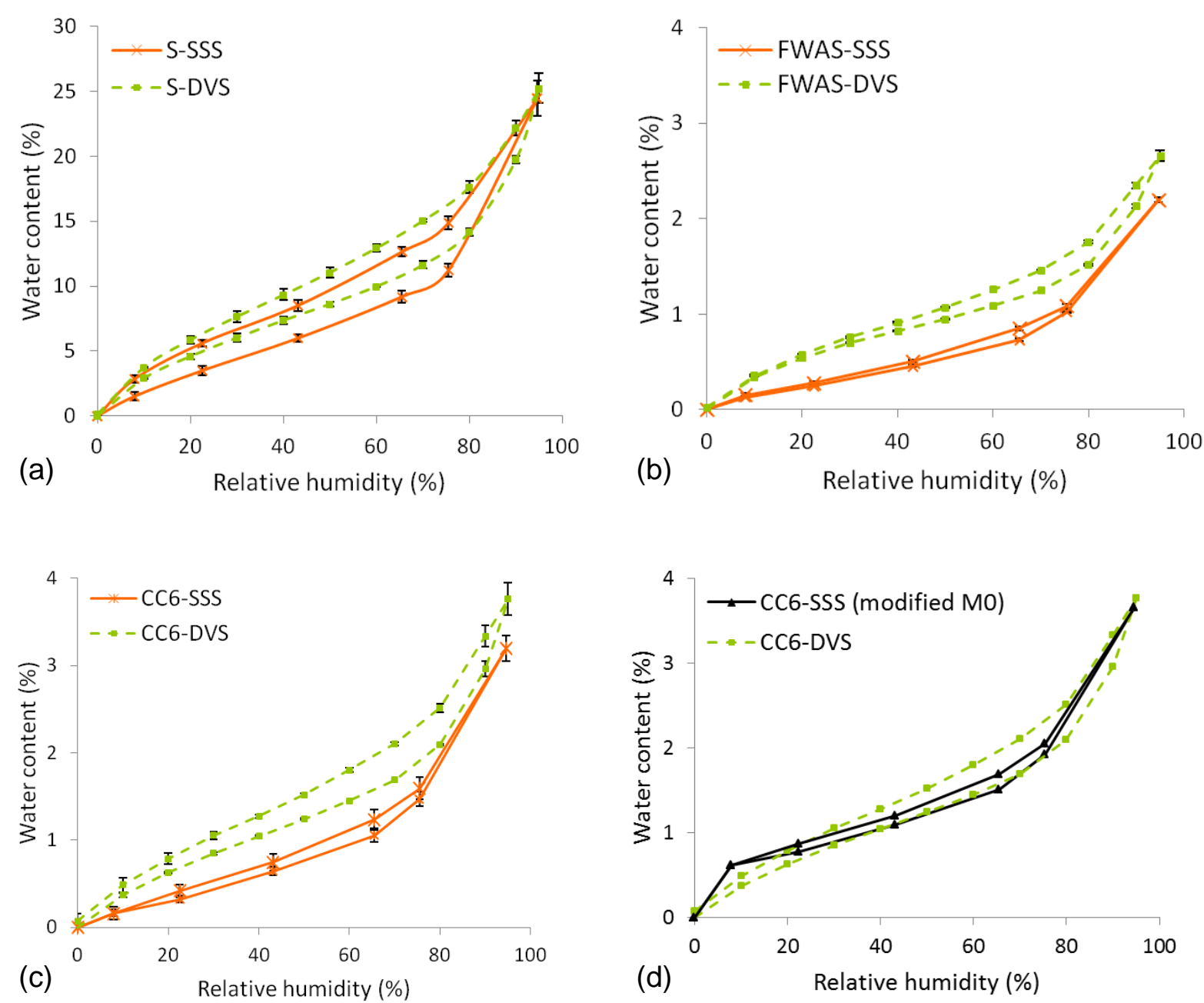

Figure 13. Comparison of the isotherm curves obtained with SSS and DVS methods: (a) bulk straw, (b) monolithic FWAS sample, (c) monolithic CC6 sample and (d) monolithic CC6 sample with a modified "dried" $M_{0}$ of $0.45 \%$ more

3.5. Prediction of the Moisture Buffer Value from the steady state properties Although it is only a theoretical value, the MBV calculated is useful to compare the various formulations of the present study. The $\mathrm{MBV}_{\text {ideal }}$ of each material is presented in

Table 7 and Figure 14.

Table 7. Calculated dynamic properties

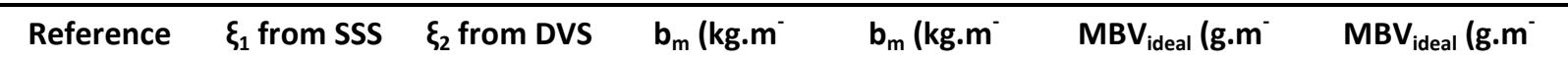




\begin{tabular}{|c|c|c|c|c|c|c|}
\hline & $\left(\mathrm{kg} \cdot \mathrm{kg}^{-1}\right)$ & $\left(\mathrm{kg} \cdot \mathrm{kg}^{-1}\right)$ & $\begin{array}{c}{ }^{2} \cdot \mathrm{Pa}^{-1} \cdot \mathrm{s}^{-1 / 2} \text { ) } \\
\text { with } \xi_{1}\end{array}$ & $\begin{array}{c}{ }^{2} \cdot \mathrm{Pa}^{-1} \cdot \mathrm{s}^{-1 / 2} \text { ) } \\
\text { with } \xi_{2}\end{array}$ & $\left.{ }^{2} . \% \mathrm{RH}^{-1}\right)$ with $\xi_{1}$ & $\left.{ }^{2} . \% \mathrm{RH}^{-1}\right)$ with $\xi_{2}$ \\
\hline FWAS & 0.0157 & 0.0154 & $6.49 \mathrm{E}-07$ & $6.42 \mathrm{E}-07$ & 3.0 & 3.0 \\
\hline S3 & 0.0182 & 0.0188 & $6.12 \mathrm{E}-07$ & $6.22 \mathrm{E}-07$ & 2.9 & 2.9 \\
\hline H3 & 0.0196 & 0.0174 & $6.62 \mathrm{E}-07$ & $6.24 \mathrm{E}-07$ & 3.1 & 2.9 \\
\hline CC3 & 0.0176 & 0.0195 & $6.32 \mathrm{E}-07$ & $6.66 \mathrm{E}-07$ & 3.0 & 3.1 \\
\hline S6 & 0.0219 & 0.0211 & 4.89E-07 & 4.81E-07 & 2.3 & 2.3 \\
\hline H6 & 0.0238 & 0.0216 & 5.86E-07 & 5.57E-07 & 2.7 & 2.6 \\
\hline CC6 & 0.0232 & 0.0235 & 7.09E-07 & 7.14E-07 & 3.3 & 3.3 \\
\hline
\end{tabular}

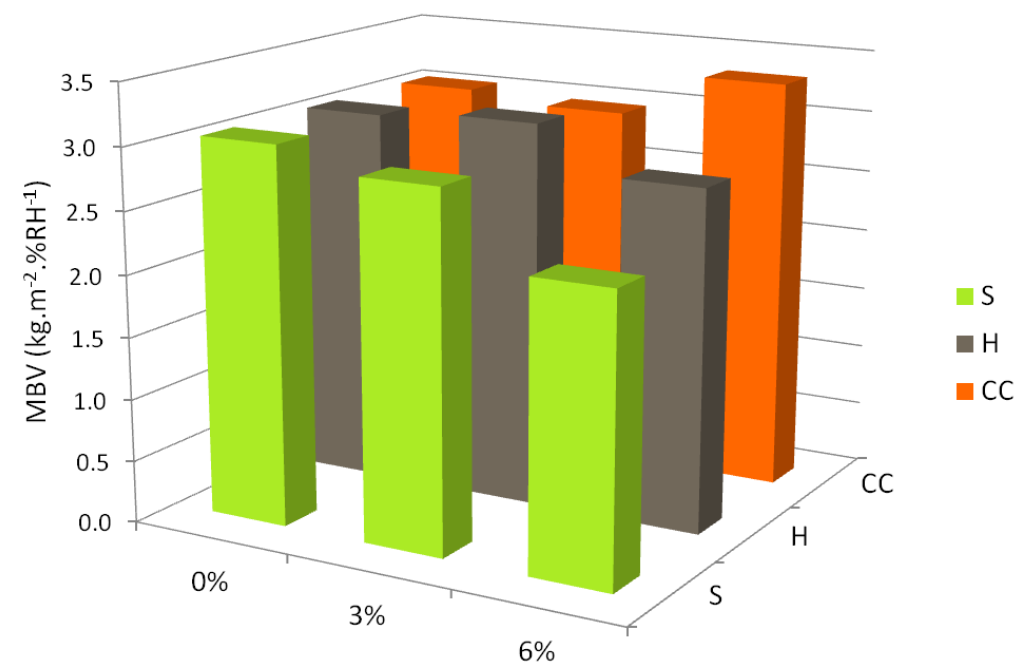

Figure 14. $M B V_{\text {ideal }}$ according to the material

The moisture buffering capacity of the materials studied here are between 2.3 and 3.3. A very small difference of value (maximum 0.2 ) can be observed between the calculations based on the SSS or the DVS experiment. For all the formulations, the $\mathrm{MBV}_{\text {ideal }}$ is above 2 . This means, according to the Nordtest classification [11], that the materials present an excellent moisture buffering capacity.

No significant effect can be observed for an addition of $3 \%$ of plant aggregates in comparison to FWAS specimens. However, the addition of $6 \%$ engenders a decrease of the $\mathrm{MBV}_{\text {ideal }}$ for the addition of straw or hemp shiv, linked to the influence of these plant aggregates on the 
water permeability, which appears to be the major factor. The increase of the value of MBV in the case of corn cob is the result of the higher density of this composite, even if the sorption (in mass) of corn cob is close to that of the other two bio-resources.

These theoretical results seem to be in accordance with some experimental values found in the literature. The MBV of unfired clay masonry measured by McGregor et al. [43] varied from 1.13 to 3.73 g.m $\mathrm{m}^{-2} . \% \mathrm{RH}^{-1}$ for similar cycles $(8 \mathrm{~h} / 16 \mathrm{~h}$ cycles at $75 \%$ and $33 \% \mathrm{RH})$. In addition, Palumbo et al. [64] found very similar results on Compressed Earth Blocks (CEB) containing $1 \%$ and $2 \%$ of barley straw by weight content: 2.6 and 2.7 g.m ${ }^{-2} . \% \mathrm{RH}^{-1}$ respectively. Whereas a small increase of the MBV can be observed with the increase of straw in the case of CEB, a small decrease has been noticed in the case of clay plaster. Indeed, the addition of $1 \%$ of barley straw in the plaster led to a slight decrease of the MBV (2.6 g. $\left.\mathrm{m}^{-2} . \% \mathrm{RH}^{-1} 1\right)$ in comparison to the clay alone $\left(2.9 \mathrm{~g} \cdot \mathrm{m}^{-2} . \% \mathrm{RH}^{-1} 1\right)$. This last observation supports the theoretical values calculated in the present study.

\section{CONCLUSION}

This paper has focused on the hygrothermal characterization of earthen materials containing several types of plant aggregates, namely barley straw, hemp shiv and corn cob. The experimental tests have shown that the addition of plant aggregates in an earth matrix improves the thermal behaviour of the material by decreasing the thermal conductivity. For example, the addition of $6 \%$ by weight of straw, corresponding to a volume of around $45 \%$, decreased the thermal conductivity by $75 \%$ with respect to the earth material without any plant aggregate. In the case of an outer wall, this decrease would allow the thickness of the additional insulating material to be reduced. However, it would not be enough to avoid using an insulating material while maintaining the thermal performance levels required by the current thermal regulations [33]. Moreover, the measurements of specific heat capacity, thermal conductivity and dry density allowed calculating thermal effusivity and diffusivity of the various mixes. The plant matter incorporation conversely affects these two properties. Despite the slight increase of specific heat capacity, the addition of plant aggregates induces 
a significant decrease of effusivity, lowering its contribution to the storage inertia. In the same time, mainly thanks to the large reduction of thermal conductivity, the addition of plant aggregates would present a positive effect on transmission inertia.

Concerning water vapour permeability, the addition of a large volume of plant aggregates, such as $6 \%$ by weight of straw or hemp shiv (corresponding to volumes of 45 and $37 \%$ respectively), limits the moisture transport slightly. However, for the other formulations, no effect on that property was observed.

The moisture storage capacity of the bulk plant aggregates is quite high in comparison to that of earth. However, the water content is expressed as the amount of water per unit mass of material. Thus, the final product presents only a slight improvement of the sorption capacity, due to the low plant matter mass. Two methods were used to assess the sorption-desorption isotherms: the saturated salt solution method and the Dynamic Vapour Sorption method. The DVS method gave higher values of sorption capacity, which might have been partly due to the definition of the dry state.

Finally, the theoretical Moisture Buffering Value was calculated. This hygric property is interesting by its dynamic nature, which gives information about the indoor moisture buffering when there are $\mathrm{RH}$ fluctuations. Although there are some differences in the isotherms between the SSS and DVS methods, no difference is observed for the $\mathrm{MBV}_{\text {ideal }}$ calculated with the two methods as the slope of the curve is taken into account, not the sorption capacity. So, in terms of moisture buffering, an addition of 3 or $6 \%$ of plant aggregates did not significantly improve the hygric behaviour of the earth alone, which already showed an excellent buffering capacity. Further studies could be carried out to measure the experimental MBV and compare the values obtained with the calculated ones.

These results have to be related with those of a complementary study focusing on mechanical properties [34]. The incorporation of low plant content has been shown to induce a significant drop in mechanical strength which would require an increase in the wall thickness to maintain a sufficient load bearing capacity. Given the global results achieved, it appears that, for a thermal resistance optimization, the incorporation of plant matter in an 
earth matrix should involve large mass proportions (dry density of the composite lower than $500 \mathrm{~kg} \cdot \mathrm{m}^{-3}$ [59], [65]). The consequence would be that the material would be neither extrudable nor load bearing. Conversely, thanks to their moisture buffering capacity and thermal inertia, the use of extruded earth bricks without plant matter would be interesting in buildings for load bearing interior walls, or outer walls if they were externally insulated.

These results highlight the need for a complementary study at building scale, in order to propose an optimized architectural design combining various earthen materials for external and indoor walls to achieve good comfort in summer together with good energy efficiency in winter. The major impact of ventilation strategies and passive solar gains should also be evaluated.

\section{ACKNOWLEDGEMENTS}

The authors wish to thank the French National Research Agency (ANR) for funding the project BIOTERRA - ANR - 13 - VBDU - 0005 Villes et Bâtiments Durables.

\section{REFERENCES}

[1] G. Minke, Building with Earth: Design and Technology of a Sustainable Architecture, Birkhäuser. Basel, Switzerland, 2006.

[2] P. Taylor, R. J. Fuller, and M. B. Luther, "Energy use and thermal comfort in a rammed earth office building," Energy and Buildings, vol. 40, no. 5, pp. 793-800, 2008.

[3] S. Liuzzi, M. R. Hall, P. Stefanizzi, and S. P. Casey, "Hygrothermal behaviour and relative humidity buffering of unfired and hydrated lime-stabilised clay composites in a Mediterranean climate," Building and Environment, vol. 61, pp. 82-92, 2013.

[4] F. McGregor, A. Heath, E. Fodde, and A. Shea, "Conditions affecting the moisture buffering measurement performed on compressed earth blocks," Building and Environment, vol. 75, pp. 11-18, 2014.

[5] F. Collet, M. Bart, L. Serres, and J. Miriel, "Porous structure and hydric properties of cob," Journal of Porous Media, vol. 13, no. 2, pp. 111-124, 2010.

[6] A. Simons et al., "Development of bio-based earth products for healthy and sustainable buildings: characterization of microbiological, mechanical and hygrothermal properties," Matériaux \& Techniques, vol. 103, no. 2, 2015.

[7] R. Bui, M. Labat, and J.-E. Aubert, "Comparison of the Saturated Salt Solution and the Dynamic Vapor Sorption techniques based on the measured sorption isotherm of barley straw," Construction and Building Materials, vol. 141, pp. 140-151, 2017.

[8] S. Dubois, F. McGregor, A. Evrard, A. Heath, and F. Lebeau, "An inverse modelling approach to estimate the hygric parameters of clay-based masonry during a Moisture Buffer Value test," Building and Environment, vol. 81, pp. 192-203, 2014. 
[9] F. Fouchal, F. Gouny, P. Maillard, L. Ulmet, and S. Rossignol, "Experimental evaluation of hydric performances of masonry walls made of earth bricks, geopolymer and wooden frame," Building and Environment, vol. 87, pp. 234-243, 2015.

[10] F. Collet, J. Chamoin, S. Pretot, and C. Lanos, "Comparison of the hygric behaviour of three hemp concretes," Energy and Buildings, vol. 62, pp. 294-303, 2013.

[11] C. Rode, R. . Peukhuri, L. . Mortensen, K. . Hansen, and A. Gustavsen, "Moisture buffering of building materials." Department of Civil Engineering, Technical University of Denmark, 2005.

[12] K. Al Rim, A. Ledhem, O. Douzane, R. M. Dheilly, and M. Queneudec, "Influence of the proportion of wood on the thermal and mechanical performances of clay-cement-wood composites," Cement and Concrete Composites, vol. 21, no. 4, pp. 269-276, 1999.

[13] S. Goodhew and R. Griffiths, "Sustainable earth walls to meet the building regulations," Energy and Buildings, vol. 37, no. 5, pp. 451-459, 2005.

[14] H. Bal, Y. Jannot, S. Gaye, and F. Demeurie, "Measurement and modelisation of the thermal conductivity of a wet composite porous medium: Laterite based bricks with millet waste additive," Construction and Building Materials, vol. 41, pp. 586-593, 2013.

[15] B. Mazhoud, F. Collet, S. Pretot, and C. Lanos, "Development and hygric and thermal characterization of hemp-clay composite," European Journal of Environmental and Civil Engineering, pp. 1-11, 2017.

[16] A. Laborel-Préneron, J. E. Aubert, C. Magniont, C. Tribout, and A. Bertron, "Plant aggregates and fibers in earth construction materials: A review," Construction and Building Materials, vol. 111, pp. 719-734, 2016.

[17] H. Binici, O. Aksogan, M. N. Bodur, E. Akca, and S. Kapur, "Thermal isolation and mechanical properties of fibre reinforced mud bricks as wall materials," Construction and Building Materials, vol. 21, no. 4, pp. 901-906, 2007.

[18] T. Ashour, H. Wieland, H. Georg, F.-J. Bockisch, and W. Wu, "The influence of natural reinforcement fibres on insulation values of earth plaster for straw bale buildings," Materials \& Design, vol. 31, no. 10, pp. 4676-4685, 2010.

[19] H. Bal, Y. Jannot, N. Quenette, A. Chenu, and S. Gaye, "Water content dependence of the porosity, density and thermal capacity of laterite based bricks with millet waste additive," Construction and Building Materials, vol. 31, pp. 144-150, 2012.

[20] P. Meukam, A. Noumowe, Y. Jannot, and R. Duval, "Caractérisation thermophysique et mécanique de briques de terre stabilisées en vue de l'isolation thermique de bâtiment," Mat. Struct., vol. 36, no. 7, pp. 453-460, 2003.

[21] H.-R. Kymäläinen and A.-M. Sjöberg, "Flax and hemp fibres as raw materials for thermal insulations," Building and Environment, vol. 43, no. 7, pp. 1261-1269, 2008.

[22] A. Bouguerra, A. Ledhem, F. de Barquin, R. M. Dheilly, and M. Quéneudec, "Effect of microstructure on the mechanical and thermal properties of lightweight concrete prepared from clay, cement, and wood aggregates," Cement and Concrete Research, vol. 28, no. 8, pp. 1179-1190, 1998.

[23] A. Brambilla and T. Jusselme, "Preventing overheating in offices through thermal inertial properties of compressed earth bricks: A study on a real scale prototype," Energy and Buildings, vol. 156, pp. 281-292, 2017.

[24] L. Soudani, M. Woloszyn, A. Fabbri, J.-C. Morel, and A.-C. Grillet, "Energy evaluation of rammed earth walls using long term in-situ measurements," Solar Energy, vol. 141, pp. 70-80, 2017.

[25] F. El Fgaier, Z. Lafhaj, E. Antczak, and C. Chapiseau, "Dynamic thermal performance of three types of unfired earth bricks," Applied Thermal Engineering, vol. 93, pp. 377-383, 2016.

[26] G. A. Abanto, M. Karkri, G. Lefebvre, M. Horn, J. L. Solis, and M. M. Gómez, "Thermal properties of adobe employed in Peruvian rural areas: Experimental results and numerical simulation of a traditional bio-composite material," Case Studies in Construction Materials, vol. 6, pp. 177-191, 2017. 
[27] AFNOR, "NF EN ISO 12571 - Performance hygrothermique des matériaux et produits pour le bâtiment - Détermination des propriétés de sorption hygroscopique." NF EN ISO 12571, 2013.

[28] C. A. S. Hill, A. Norton, and G. Newman, "The water vapor sorption behavior of natural fibers," Journal of Applied Polymer Science, vol. 112, no. 3, pp. 1524-1537, 2009.

[29] H. Cagnon, J. E. Aubert, M. Coutand, and C. Magniont, "Hygrothermal properties of earth bricks," Energy and Buildings, vol. 80, pp. 208-217, 2014.

[30] Z. Pavlík, J. Žumár, I. Medved, and R. Černý, "Water Vapor Adsorption in Porous Building Materials: Experimental Measurement and Theoretical Analysis," Transport in Porous Media, vol. 91, no. 3, pp. 939-954, 2012.

[31] S. J. Schmidt and J. W. Lee, "Comparison Between Water Vapor Sorption Isotherms Obtained Using The New Dynamic Dewpoint Isotherm Method and those Obtained Using The Standard Saturated Salt Slurry Method," International Journal of Food Properties, vol. 15, no. 2, pp. 236-248, 2012.

[32] M. Palumbo, "Contribution to the development of new bio-based thermal insulation materials made from vegetal pith and natural binders," PhD Thesis, Universitat Politècnica de Catalunya, Barcelona, 2015.

[33] A. Laborel-Préneron, C. Magniont, and J.-E. Aubert, "Characterization of barley straw, hemp shiv and corn cob as resources for bioaggregate based building materials," Waste and Biomass Valorization, 2017. 10.1007/s12649-017-9895-z

[34] A. Laborel-Préneron, J.-E. Aubert, C. Magniont, P. Maillard, and C. Poirier, "Effect of plant aggregates on mechanical properties of earth bricks," Journal of Materials in Civil Engineering, vol. 29, no. 12, 2017.

[35] International Organisation for Standardization, "ISO 8302 - Thermal insulation Determination of steady-state thermal resistance and related properties - Guarded hot plate apparatus." 1991.

[36] European Standards, "EN 12667 - Thermal performance of building materials and products - Determination of thermal resistance by means of guarded hot plate and heat flow meter methods - Products of high and medium thermal resistance." 2001.

[37] AFNOR, "Plastics - Differential scanning calorimetry (DSC) - Part 4: Determination of specific heat capacity." NF EN 11357-4, 2014.

[38] B. Seng, C. Magniont, S. Spagnol, and S. Lorente, "Assessment of a precast hemp concrete hygrothermal properties," in Proceedings of the 2nd International Conference on Bio-Based Building Materials, Clermont-Ferrand, France, 2017, pp. 386-393.

[39] AFNOR, "NF EN ISO 12572 - Performance hygrothermique des matériaux et produits pour le bâtiment - Détermination des propriétés de transmission de la vapeur d'eau." NF EN ISO 12572, 2001.

[40] ASTM, "E96/E96M-10 - Standard test methods for water vapor transmission of materials." American Society for Testing and Materials, 2010.

[41] P. W. Winston and D. H. Bates, "Saturated Solutions For the Control of Humidity in Biological Research," Ecology, vol. 41, no. 1, pp. 232-237, 1960.

[42] C. Feng, H. Janssen, Y. Feng, and Q. Meng, "Hygric properties of porous building materials: Analysis of measurement repeatability and reproducibility," Building and Environment, vol. 85, pp. 160-172, 2015.

[43] F. McGregor, A. Heath, A. Shea, and M. Lawrence, "The moisture buffering capacity of unfired clay masonry," Building and Environment, vol. 82, pp. 599-607, 2014.

[44] M. Bachar, L. Azzouz, M. Rabehi, and B. Mezghiche, "Characterization of a stabilized earth concrete and the effect of incorporation of aggregates of cork on its thermomechanical properties: Experimental study and modeling," Construction and Building Materials, vol. 74, pp. 259-267, 2015.

[45] J.-P. Laurent, "études et recherches, Propriétés thermiques du matériau terre", CSTB 1987.

[46] J. Khedari, P. Watsanasathaporn, and J. Hirunlabh, "Development of fibre-based soilcement block with low thermal conductivity," Cement and Concrete Composites, vol. 27, no. 1, pp. 111-116, 2005. 
[47] S. Mounir, Y. Maaloufa, A. bakr Cherki, and A. Khabbazi, "Thermal properties of the composite material clay/granular cork," Construction and Building Materials, vol. 70, pp. 183-190, 2014.

[48] P. K. Latha, Y. Darshana, and V. Venugopal, "Role of building material in thermal comfort in tropical climates - A review," Journal of Building Engineering, vol. 3, pp. 104113, 2015.

[49] D. Medjelekh, L. Ulmet, S. Abdou, and F. Dubois, "A field study of thermal and hygric inertia and its effects on indoor thermal comfort: Characterization of travertine stone envelope," Building and Environment, vol. 106, pp. 57-77, 2016.

[50] A. Jeanjean, R. Olives, and X. Py, "Selection criteria of thermal mass materials for lowenergy building construction applied to conventional and alternative materials," Energy and Buildings, vol. 63, pp. 36-48, 2013.

[51] P. M. Touré, V. Sambou, M. Faye, A. Thiam, M. Adj, and D. Azilinon, "Mechanical and hygrothermal properties of compressed stabilized earth bricks (CSEB)," Journal of Building Engineering, vol. 13, pp. 266-271, 2017.

[52] P. Faria, T. Santos, and J.-E. Aubert, "Experimental characterization of an earth ecoefficient plastering mortar," Journal of Materials in Civil Engineering, vol. 28, no. 1, 2016.

[53] M. O'Farrell, S. Wild, and B. B. Sabir, "Pore size distribution and compressive strength of waste clay brick mortar," Cement and Concrete Composites, vol. 23, no. 1, pp. 8191, 2001.

[54] A. W. Bruno, "Hygro-mechanical characterisation of hypercompacted earth for sustainable construction," PhD dissertation of Philosophy in Civil Engineering, Université de Pau et des pays de l'Adour, Pau, France, 2016.

[55] CSTB, "Règles, Fascicule 2: Matériaux." 2012.

[56] C. Maalouf, B. S. Umurigirwa, N. Viens, M. Lachi, and T. H. Mai, "Study of the hygric behaviour and moisture buffering performance of a hemp-starch composite panet for buildings," BioResources, vol. 10, no. 1, 2015.

[57] International Union of Pure and Applied Chemistry, "Reporting physisorption data for gas/solid systems with special reference to the determination of surface area and porosity," Pure and Applied Chemistry, vol. 57, no. 4, pp. 603-619, 1985.

[58] T. Ashour, H. Georg, and W. Wu, "An experimental investigation on equilibrium moisture content of earth plaster with natural reinforcement fibres for straw bale buildings," Applied Thermal Engineering, vol. 31, no. 2-3, pp. 293-303, 2011.

[59] M. Labat, C. Magniont, N. Oudhof, and J.-E. Aubert, "From the experimental characterization of the hygrothermal properties of straw-clay mixtures to the numerical assessment of their buffering potential," Building and Environment, vol. 97, pp. 69-81, 2016.

[60] F. El Fgaier, Z. Lafhaj, C. Chapiseau, and E. Antczak, "Effect of sorption capacity on thermo-mechanical properties of unfired clay bricks," Journal of Building Engineering, vol. 6, pp. 86-92, 2016.

[61] V. Baroghel-Bouny, "Water vapour sorption experiments on hardened cementitious materials," Cement and Concrete Research, vol. 37, no. 3, pp. 414-437, 2007.

[62] L. Wadsö, K. Svennberg, and A. Dueck, "An Experimentally Simple Method for Measuring Sorption Isotherms," Drying Technology, vol. 22, no. 10, pp. 2427-2440, 2004.

[63] AFNOR, "NF EN ISO 12570 - Performance hygrothermique des matériaux et produits pour le bâtiment - Détermination du taux d'humidité par séchage à chaud." 2000.

[64] M. Palumbo, F. McGregor, A. Heath, and P. Walker, "The influence of two crop byproducts on the hygrothermal properties of earth plasters," Building and Environment, vol. 105, pp. 245-252, 2016.

[65] T. Vinceslas, T. Colinart, E. Hamard, A. Hellouin de Ménibus, T. Lecompte, and H. Lenormand, "Light earth performances for thermal insulation: application to earthhemp," in Proceedings of the 2nd International Conference on Bio-Based Building Materials, Clermont-Ferrand, France, 2017, pp. 173-179. 